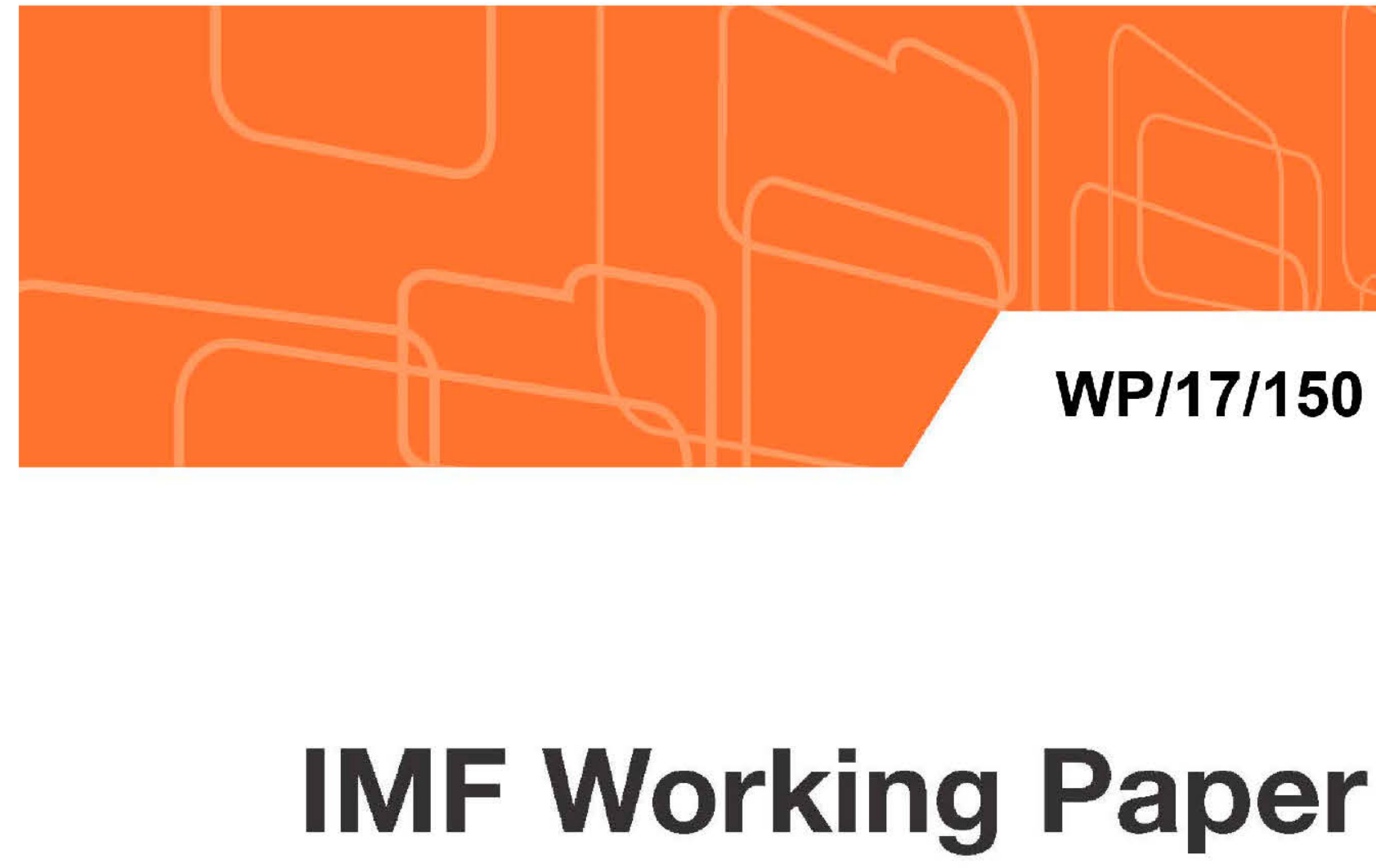

\title{
Panama's Growth Prospects: Determinants and Sectoral Perspectives
}

Kimberly Beaton and Metodij Hadzi-Vaskov

IMF Working Papers describe research in progress by the author(s) and are published to elicit comments and to encourage debate. The views expressed in IMF Working Papers are those of the author(s) and do not necessarily represent the views of the IMF, its Executive Board, or IMF management. 


\section{WP/17/150}

\section{IMF Working Paper}

\section{Panama's Growth Prospects: Determinants and Sectoral Perspectives}

Kimberly Beaton and Metodij Hadzi-Vaskov

IMF Working Papers describe research in progress by the author(s) and are published to elicit comments and to encourage debate. The views expressed in IMF Working Papers are those of the author(s) and do not necessarily represent the views of the IMF, its Executive Board, or IMF management. 


\title{
IMF Working Paper
}

Western Hemisphere Department

\section{Panama's Growth Prospects: Determinants and Sectoral Perspectives \\ Prepared by Kimberly Beaton and Metodij Hadzi-Vaskov}

Authorized for distribution by Valerie Cerra

July 2017

\section{IMF Working Papers describe research in progress by the author(s) and are published to elicit comments and to encourage debate. The views expressed in IMF Working Papers are those of the author(s) and do not necessarily represent the views of the IMF, its Executive Board, or IMF management.}

\begin{abstract}
This paper estimates medium-term potential growth for a country undergoing significant structural and secular changes. Our forward-looking framework, incorporating three analytical approaches for examining economic prospects, constitutes an important complement to typical backward-looking methods that filter or extrapolate historical data. In particular, the opening of the expanded Panama Canal in 2016 highlights significant structural changes underway in the Panamanian economy. We first analyze growth determinants and find that Panama is well-placed to maintain its business model, with improvements in education and governance important to support growth. Second, the current pipeline of investment projects can help sustain investment-led growth, although at a more moderate pace. Third, further development of the logistics and tourism sectors holds promise to further build on Panama's comparative advantage.
\end{abstract}

JEL Classification Numbers: H54, O54, Z32

Keywords: Economic Growth, Potential Growth, Potential Output, Growth Determinants, Case Study, Investment, Infrastructure, Logistics, Tourism, Panama

Author's E-Mail Address: KBeaton@imf.org; MHadziVaskov@,imf.org 

ABSTRACT
I. INTRODUCTION
II. DETERMINANTS OF GROWTH: HOW DOES PANAMA COMPARE?
A. Recent Growth Performance
B. Growth Determinants

III. INVESTMENT AS A DRIVER OF GROWTH: CAN HIGH INVESTMENT BE SUSTAINED OVER THE MEDIUM-TERM?

A. Contribution to Growth from Large-scale Investment Projects

B. Growth Accounting and Factors of Production

IV. TRANSFORMING PANAMA INTO A GLOBAL LOGISTICS HUB: WHAT CAN PANAMA LEARN FROM SINGAPORE?

A. Singapore's Success Story

B. Where Does Panama Stand?

V. LEVERAGING CONNECTIVITY TO STRENGTHEN TOURISM

A. Panama's Tourism Sector - Taking Stock $-\frac{23}{23}$

B. Performance of the Tourism Sector

C. Opportunities to Strengthen Panama's Tourism Sector

VI. CONCLUSIONS $\underline{29}$

VII. REFERENCES

\section{FIGURES}

1.: Recent Economic Performance

2. Infrastructure Quality Indicators Relative to GDP per Capita (2014)

3. Education Performance

4. Cost of Finance

5.Survey-based Competitiveness Indictors

6. Singapore: Sectoral Performance

7. Port Performance

8. Panama and Singapore: Logistics Peformance Index

9. Panama and Singapore: Survey-based Competitiveness Indictors

10. Tourism's Contribution to the Economy

11. Tourism Arrivals by Market

12. Tourism Sector Competitiveness

13. Tourism Performance and Market Share

\section{TABLES}

1: Overview of Ongoing and Planned Investment Projects

2. Growth Accounting: Estimated Average Contribution to Growth

3. Singapore and Panama: Comparing Logistics-Relevant Features 


\section{INTRODUCTION}

The opening of the expanded Panama Canal in June 2016 marks a key milestone in Panama's history as an important water route for world trade, and presents a unique opportunity to reevaluate Panama's growth model. As a major investment project, the Canal expansion provided an important impetus to Panama's strong growth performance over 2007-16. Going forward, the expansion, designed to accommodate "post-Panama" vessels and roughly double the Canal's capacity, is expected to open new opportunities for emerging activities (such as transit of LPG and LNG vessels) and strengthen growth prospects for related industries such as ports and logistics. Hence, as an important structural change, the completion of the expanded Canal provides an opportune time to reassess Panama's medium-term economic prospects.

Studies that aim to assess an economy's growth prospects typically employ a variety of filters and data techniques based on historical data series to estimate potential growth. As such, the relevance of all these backward-looking methodologies may be significantly reduced when structural changes take place in the economy that make the use of historical data inadequate for assessing future growth prospects. In light of this, the current paper follows an innovate forward-looking approach that may be better suited to assess potential output and medium-term growth prospects at times of large changes in the economy. Instead of relying on backwardlooking data techniques to filter or extrapolate historical data series, this paper follows a forward-looking eclectic approach that aims to capture prospective trends in the economy from different perspectives and analytical angles. Our eclectic approach combines an assessment of Panama's growth determinants with a deeper analysis of investment as a driver of growth and case studies of the logistics and tourism sectors.

The rest of the paper is organized as follows. Section II looks at Panama's growth determinants and compares them with peer countries. Section III assesses the importance of investment as a driver of economic growth, with a focus on the contribution from the existing pipeline of public and private investment projects. Sections IV and V provide case studies that examine Panama's potential to further exploit its comparative advantage in the logistics and tourism sectors. Section VI concludes. 


\section{Determinants of Growth: How Does Panama Compare?}

Panama has had exceptional growth performance over recent decades. This section explores the determinants of Panama's growth to assess prospects for this growth to continue and identifies improving the quality of education, strengthening governance and reducing bureaucracy as the growth policy priorities for Panama to maintain its business model and further cement Panama's competitiveness.

\section{A. Recent Growth Performance}

Panama has had the highest growth in LAC over the past two decades. This has resulted in a significant increase in its per capita income, which has doubled since 2004, and strong convergence of its income per capita with advanced economies. Exceptionally strong growth also contributed to an improvement in social-economic conditions, with important declines in poverty and income inequality (Figure 1). More recently, growth has begun to slow from its exceptionally high rates, reaching 4.9 percent in 2016 . The moderation has been primarily associated with a slowdown of construction, including due to the completion of the expansion of the Panama Canal. In this context, the economy appears to have reached a turning point where the drivers of growth may be shifting from construction to services. While Section III suggests that investment will continue to be supportive of growth and Sections IV and V consider two service sectors that hold potential to emerge as important pillars of the Panamanian economy, this section assesses the extent to which the overall policy framework and macroeconomic and financial conditions remain supportive of growth and to what extent policy can play a role in helping to smooth the ongoing transition of the Panamanian economy to services.

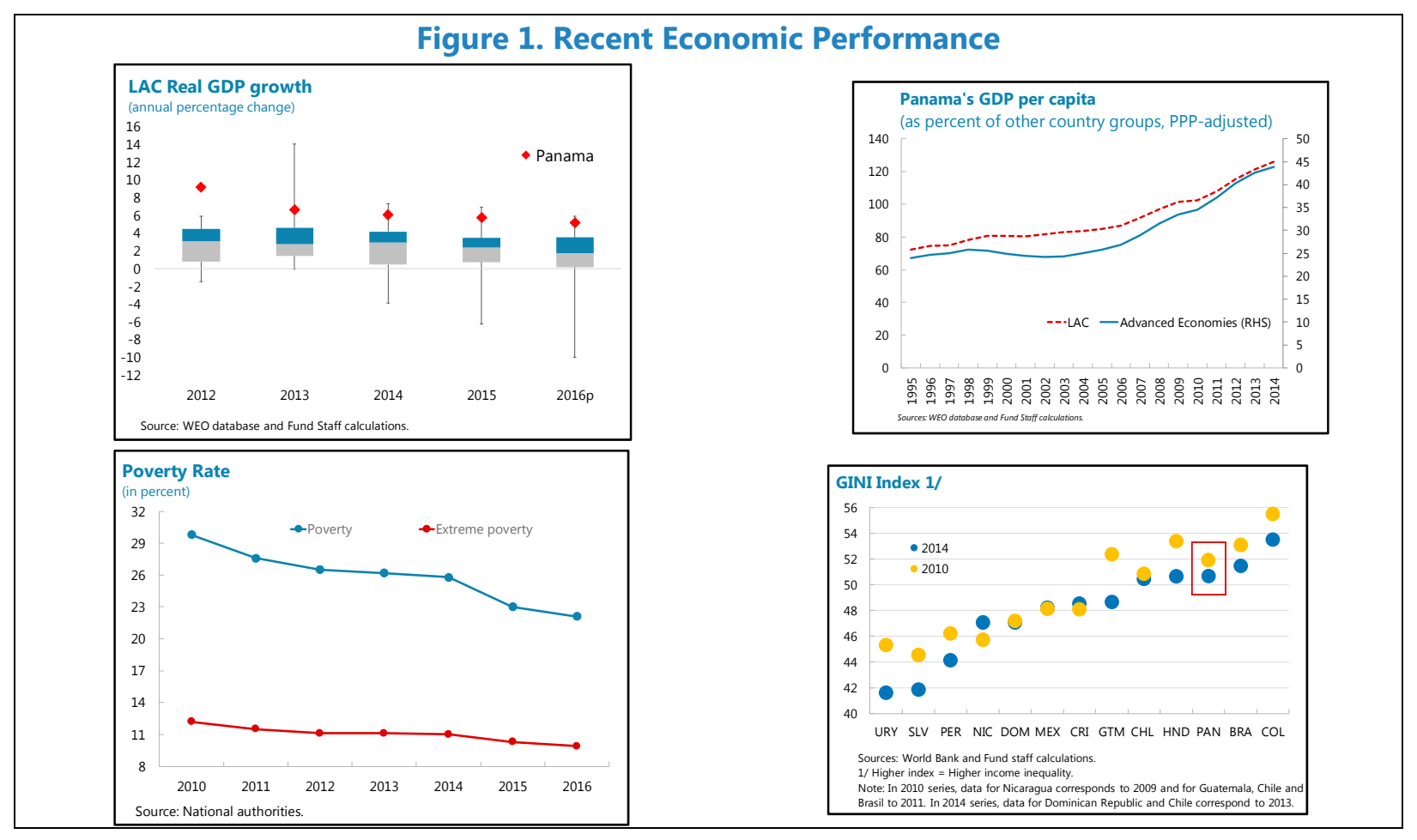




\section{B. Growth Determinants}

How can Panama improve its medium-term growth prospects? A precondition to designing effective growth policies is an understanding of an economy's binding constraints to growth. In this section, we assess Panama's relative performance in across a variety of growth determinants including infrastructure, education, access and cost of finance and the overall business environment. Based on this analysis, we identify the binding constraints to growth for Panama and recommend specific policies to strengthen medium-term growth prospects.

\section{Infrastructure}

Overall infrastructure quality is high in the regional context and supportive of investment. Panama ranks highly in overall infrastructure quality, according to the World Economic Forum, particularly compared to its peers in Latin America and the Caribbean (see Figure 2). The high overall ranking can be directly linked to Panama's role as a regional transportation hub: the quality of air transportation infrastructure benefits from Tocumen airport's role as a regional hub and, similarly, the quality of port infrastructure far exceeds other countries in Latin America due primarily to the Panama Canal. The quality of road transportation also ranks amongst the highest in Latin America. With the importance of the Panama Canal and related port and logistics activity, Panama is highly competitive in logistics with supportive infrastructure and related processes (e.g. customs) in place. Recent and ongoing infrastructure projects promise to further strengthen Panama's supportive infrastructure in these areas: the Panama Canal expansion began commercial operations in June 2016 and the extensive expansion of the Tocumen airport is expected to be completed in

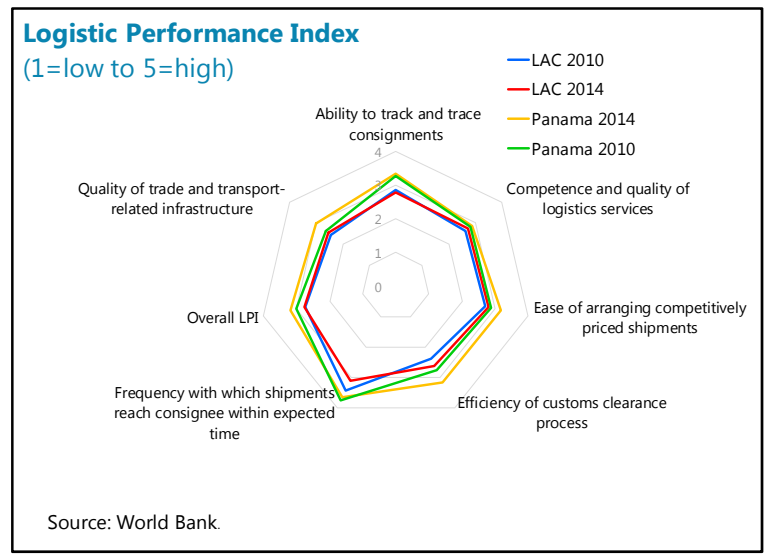
2018.

Energy and communications infrastructure are also supportive of growth. As with transportation and logistics infrastructure, the quality of Panama's energy infrastructure compares favorably to other countries in Latin America, although its comparative advantage is not as striking as with the former. Panama is a net exporter of electricity, exporting electricity to Costa Rica. New transmission lines are in the process of being constructed (see Section III) that will enable Panama to increase its electricity exports, with potential to export to South America. With respect to communications infrastructure, Panama is a regional telecommunications hub as the Panama Canal is the interconnection point of several international fiber submarine cables. Despite this advantageous position, internet usage is low compared to other countries in Latin America. Hausmann, Espinoza, and Santos (2016) conjecture that this puzzle may be related to income inequalities and associated differences in the coverage of the internet grid across Panama, an explanation that bears credence. 
Figure 2. Infrastructure Quality Indicators Relative to GDP per Capita (2014) (Y-axis: Infrastructure quality index, $0=$ worst, $7=$ best; $\mathrm{X}$-axis: GDP per capita, PPP dollars, log-scale)

\section{Overall Infrastructure}

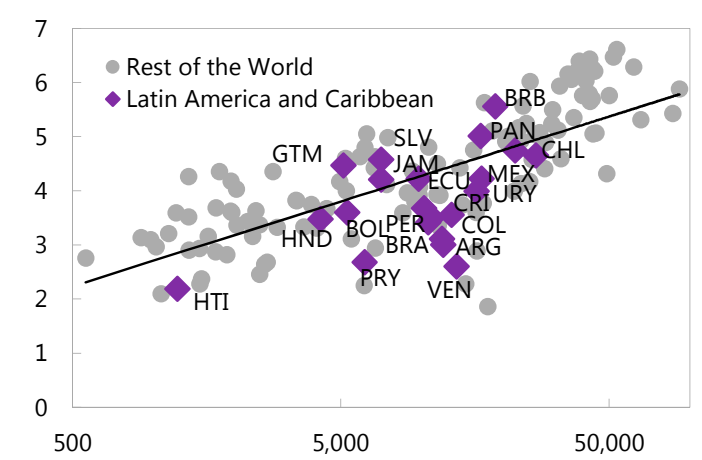

\section{Roads}

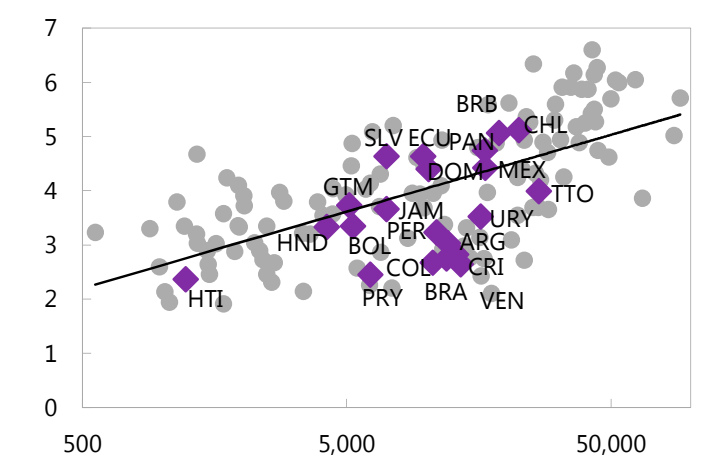

Air Transport

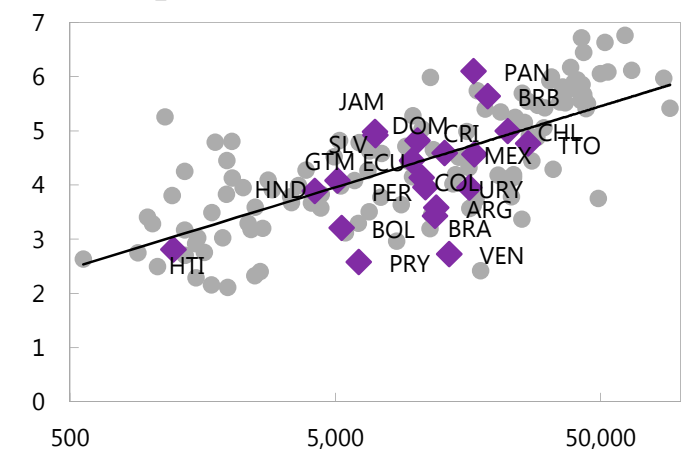

\section{Electricity Supply}

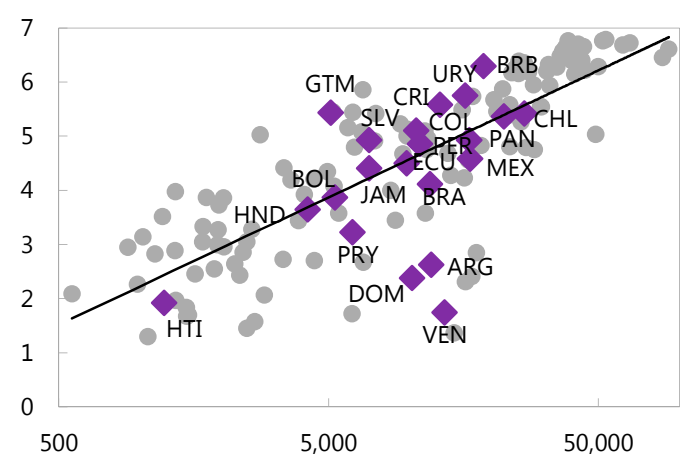

\section{Railroads}

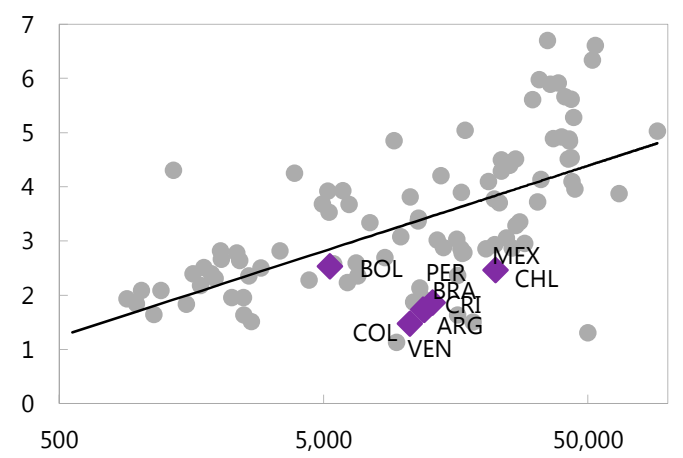

\section{Ports}

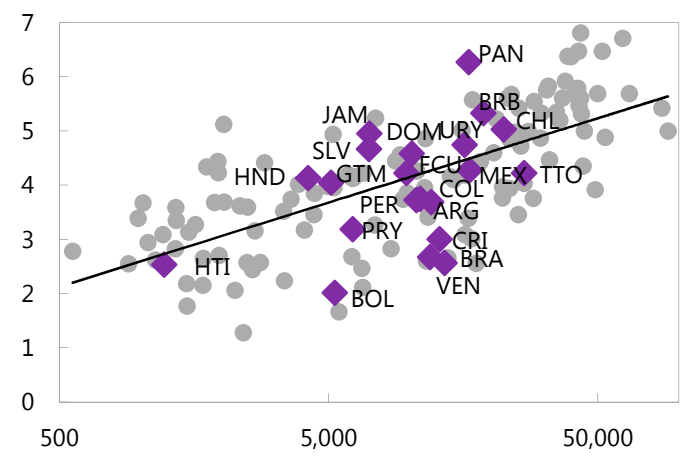

Sources: Cerra and others (2016). World Economic Forum; and IMF staff calculations. Note: ARG = Argentina; BRA = Brazil; $\mathrm{CHL}=$ Chile; $\mathrm{CRC}=$ Costa Rica $\mathrm{COL}=$ Colombia;DOM $=$ Dominican Republic; $\mathrm{ECU}=$ Ecuador; ESV $=\mathrm{E} 1$ Salvador; GTM = Guatemala; HON = Honduras; JAM = Jamaica; MEX = Mexico; NIC = Nicaragua; PAN = Panama; PRY = Paraguay; PER = Peru; TTO = Trinidad and Tobago; URY = Uruguay; VEN = Venezuela. 


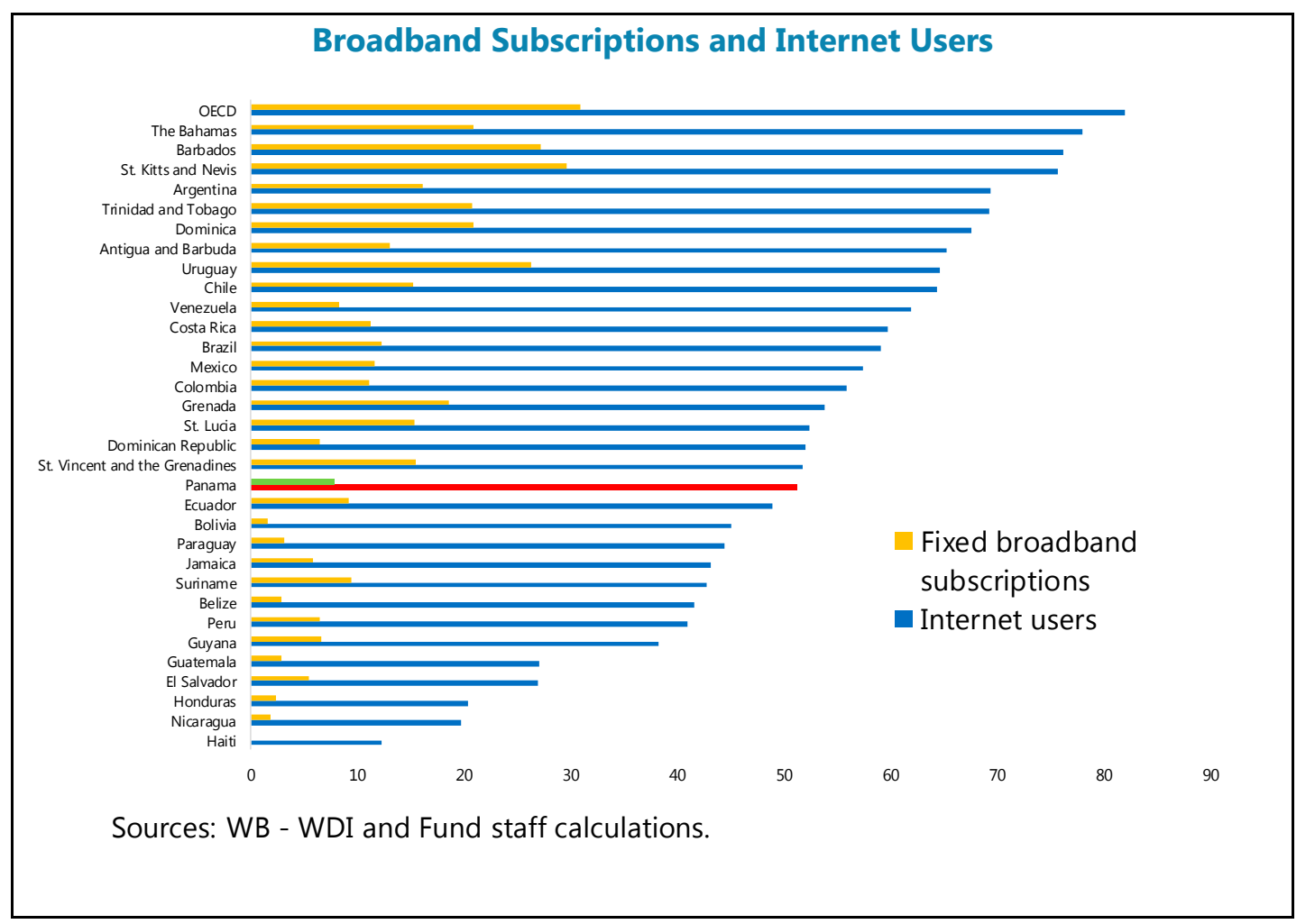

\section{Education}

Strengthening the quality of education will be important to improve growth prospects. The Panamanian workforce has a higher level of educational attainment than other countries in Central America and the Dominican Republic, but this has not translated into improved educational outcomes (Figure 3). Panama has both a higher share of secondary/tertiary graduates and average years of schooling of its population than comparator countries. Yet, Panama has performed poorly in international competency tests. For example, its performance in the 2013 TERCE test that assessed competency of third and sixth graders in Latin America across a variety of subjects suggests that educational quality is below that of most countries in Latin America. ${ }^{1}$

Performance was particularly weak in mathematics and reading comprehension. More generally, Panama has underperformed the Latin American region on the education and training subindex of the World Economic Forum's Global Competitiveness Index and an inadequately educated workforce

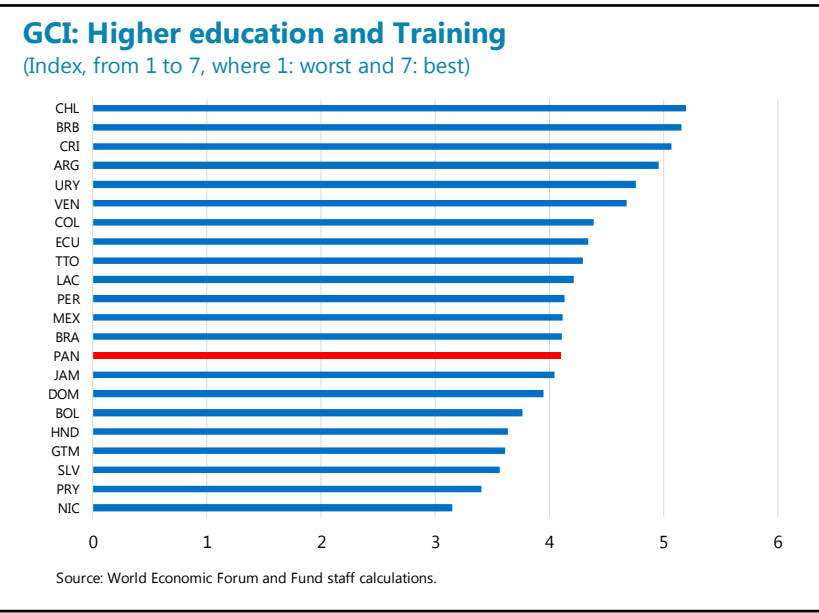

\footnotetext{
${ }^{1}$ See also IMF Country Report No. 16/338.
} 
is the third most frequently cited problematic factor for doing business in Panama in its 2016-17 Global Competitiveness Report. Finally, there are indications that there may be a mismatch between the skills demanded by the Panamanian economy and those provided by the workforce, particularly as the economy continues its transition to a service-based economy increasing the demand for more skilled workers., ${ }^{2,3}$ In this regard, the government's renewed emphasis on education reform, including the new technical institute to address skills gaps will be key to moving up the value chain, especially in services.

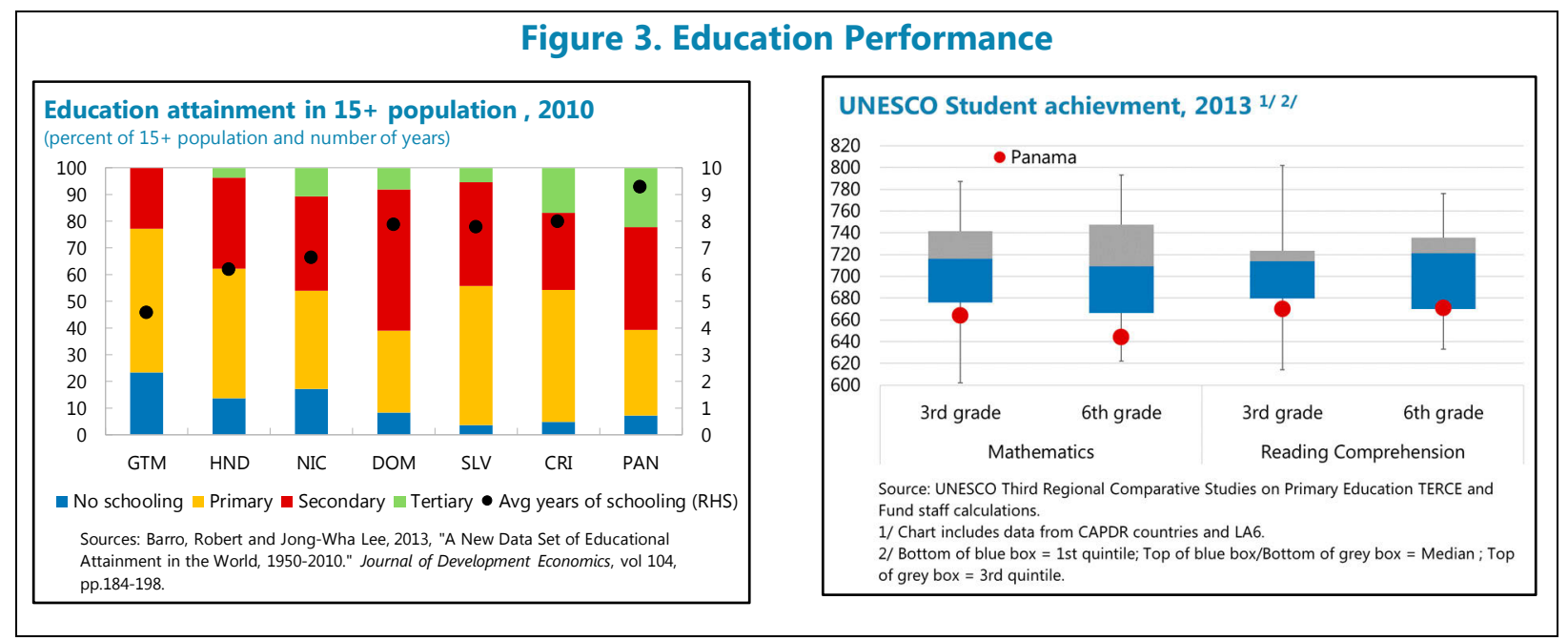

\section{Cost of Finance}

Panama is a regional financial center. Financial sector assets are sizeable at 238 percent of GDP. Banks dominate the system, representing about 90 percent of assets, with offshore banks holding about 16 percent of bank assets. ${ }^{4}$ The banking system is highly competitive with 55 banks serving the domestic economy, including two state-owned banks. Credit to the domestic private sector is high compared to regional standards and Panama's level of economic development. ${ }^{5}$ Panama also ranks highly, particularly compared to its Latin American peers, in terms of financial development and ease of access to credit. The highly competitive financial sector has also contributed to a low cost of finance, with the real lending rate amongst the lowest in Latin America (Figure 4).

\footnotetext{
${ }^{2}$ See Hausmann, Espinoza and Santos (2016) for a more detailed analysis of the demand-supply imbalances in the Panamanian labor market.

${ }^{3}$ The Talent Shortage Survey 2016/2017 conducted by Manpower Group suggests that Panama especially lacks qualified technicians.

${ }^{4}$ Offshore banks are prohibited from conducting domestic banking operations and accept deposits and provide credit only outside of Panama.

${ }^{5}$ Despite strong credit growth, the credit gap is only modestly positive. However, Panama has experienced a prolonged credit boom since 2000, when credit data became available, suggesting that credit risks may be higher than suggested by the credit gap.
} 


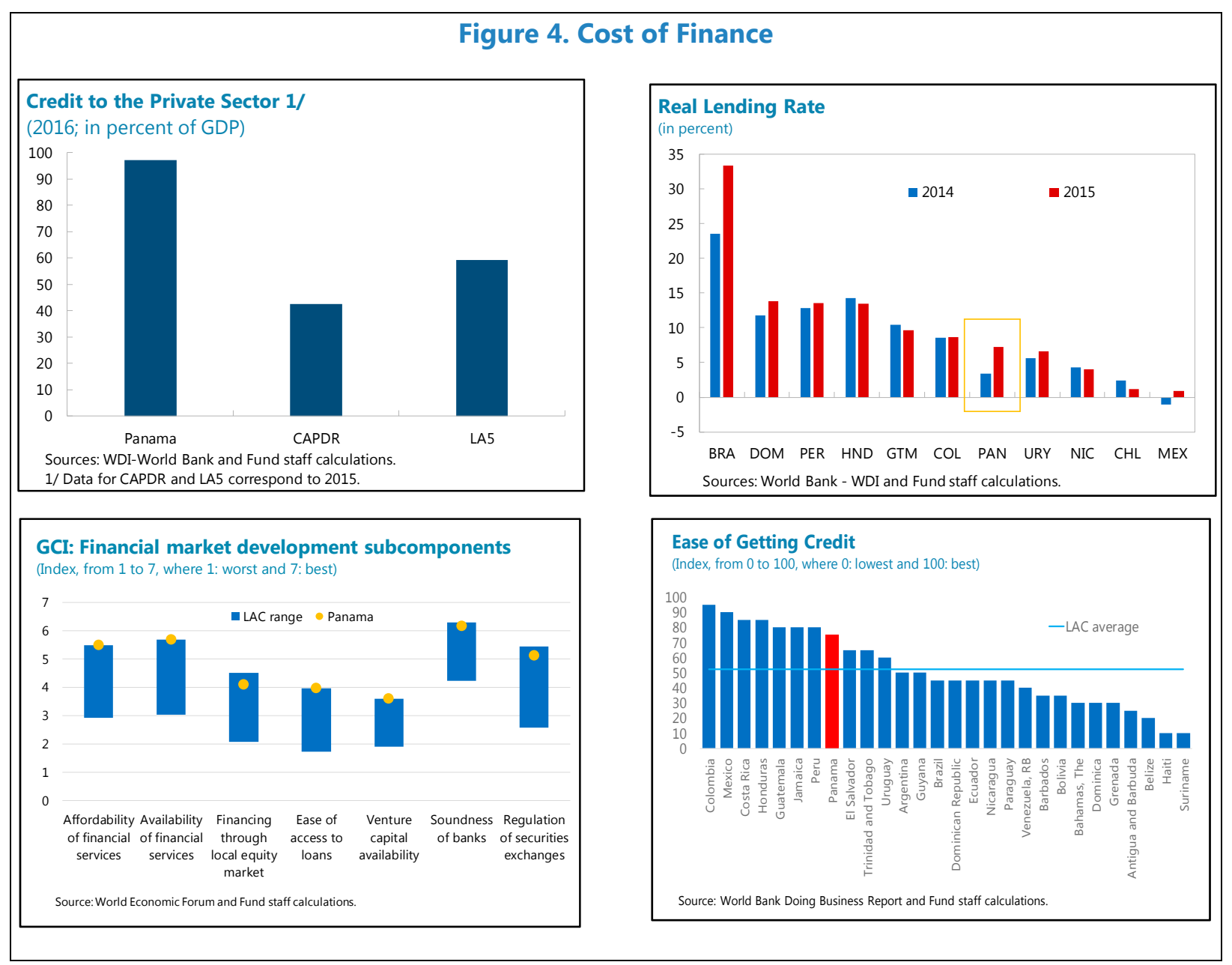

\section{Business Environment}

Macroeconomic prospects benefit from Panama's macroeconomic policy framework, anchored in fiscal discipline and financial sector stability. In addition to strong growth performance over recent years, the economy has benefited from price stability and low unemployment. Fiscal policy remains sustainable — rooted in the Social Fiscal Responsibility Law (SFRL), with public debt projected to remain below the SFRL target of 40 percent of GDP. The regional financial center has also been a source of stability, although macro-financial risks from the prolonged credit expansion remain a concern. In this context, a continued strengthening of financial sector oversight, particularly of systemic risks, will be important to safeguarding financial stability and ensuring that financial conditions remain supportive of growth. Development of a macroprudential policy framework and associated tools and a strengthening of the crisis management framework, including through a liquidity facility for banks, would be important complements. 
At the microeconomic level, risks primarily relate to the need to strengthen governance and reduce bureaucracy. Typical risks tend to relate to tax regimes, labor market rigidities, and the general business environment including the extent of bureaucracy, crime and corruption. Tax rates and tax administration are unlikely to be a barrier to growth for Panama: Panama's tax-toGDP ratio is amongst the lowest in Latin America and tax rates are generally lower than other countries in the region (both for direct and indirect taxes). Panama also performs well compared to other Latin American countries in labor market efficiency and a wide range of indicators with respect to the overall business environment including starting a business, obtaining construction permits, and registering property (Figure 5). Nevertheless, inefficient government bureaucracy is one of the identified most problematic factors for doing business in Panama and there is room for improvement. The key priority for reducing microeconomic risks will be to strengthen governance (text figure).

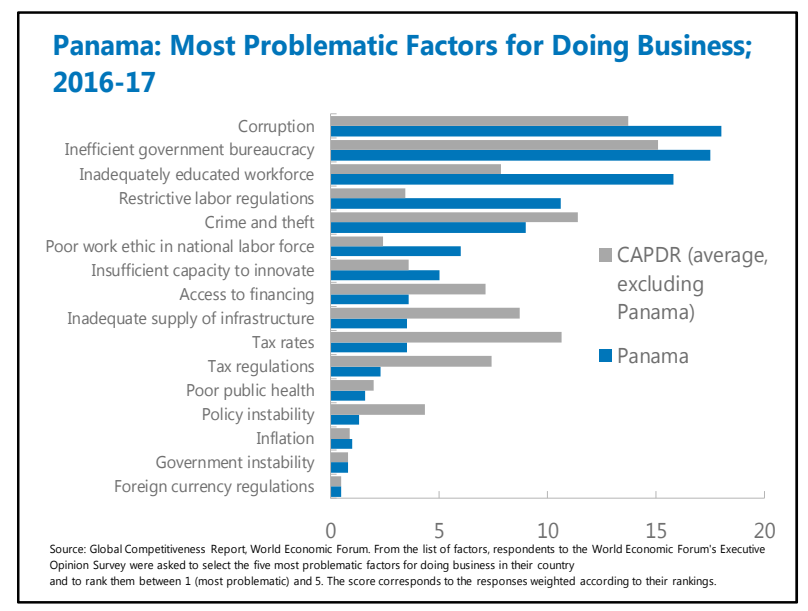

Figure 5. Survey-based Competitiveness Indictors
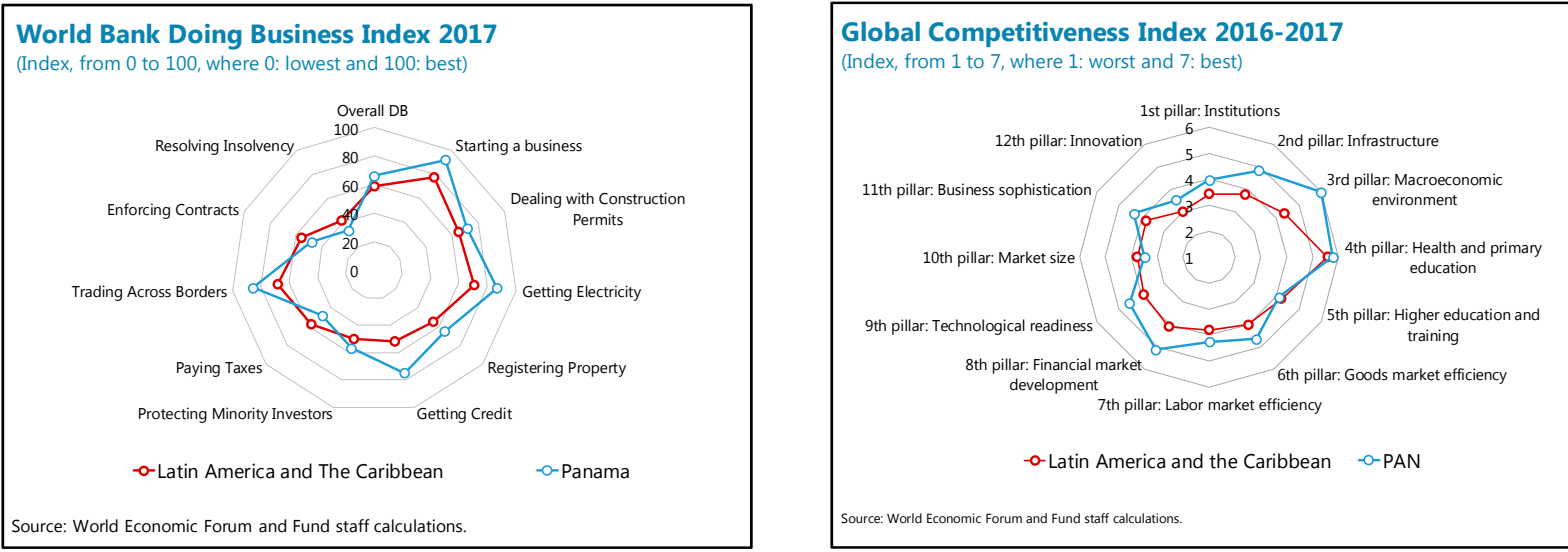

The growth diagnostic exercise confirms that Panama is well-placed to maintain its business model. The results of the diagnostic suggest that the most important challenge will be to advance reforms to the education system to ensure that the system is able to supply workers with the skills demanded in Panama's economy. In particular, addressing existing skills gaps will be key to moving up the value chain in services. Reducing bureaucracy and strengthening governance can also have important growth dividends. 


\section{InVESTMENT AS A DRIVER OF GROWTH: CAN High INVESTMENT BE SUSTAINED OVER THE MEDIUM-TERM?}

Investment played a central role in Panama's successful growth story over the past decade. This section takes stock of investment's historical contribution to growth and assesses prospects to sustain investment-led growth. Based on the existing pipeline of public and private investment projects, estimates of their direct and indirect growth effects suggest that investment-led growth can be sustained, although at a more sustainable rate than in the recent past.

\section{A. Contribution to Growth from Large-scale Investment Projects}

Large investment projects contributed strongly to Panama's exceptional growth in recent years. Besides the expansion of the Panama Canal, the largest investment project (estimated at about US\$5.3 billion over 2007-16), several other large-scale projects were completed in recent years, including Metro line I, several highway sections, the Cinta Costera, and the urban renovation of Panama City's old town. Overall, investment (public and private) is estimated to have contributed on average 4 percentage points to Panama's annual economic growth over the period 2008-2016.

There is an extensive pipeline of ongoing and planned investment projects. Table 1 provides an overview of some of the largest projects under construction or in an advanced planning stage. Their total value is estimated at US\$16.7 billion, or about 30.3 percent of Panama's 2016 GDP. The largest private investment project Minera Panamá, with an estimated total value of US\$5.5 billion (with US\$2 billion remaining to be executed until its expected completion in 2018), surpasses the total investment value of the Panama Canal expansion.

The wide range of investment projects can provide a significant boost to Panama's medium-term economic activity. First, new investment will directly boost construction and other sectors of the economy. This effect increases with the inverse of the investment's import content. Second, investment projects affect the economy indirectly through multiplier effects across different sectors that follow the direct impact of construction activity. Third, new investment can increase the economy's productive capacity and strengthen its potential growth, particularly when projects address bottlenecks and improve efficiency. This analysis sheds light on all three aspects. 


\begin{tabular}{|c|c|c|}
\hline Project & Value & Status \\
\hline Public/government & 8.94 & \\
\hline Metro line 2 & 2.10 & onqoing \\
\hline Tocumen terminal expansion & 0.90 & ongoing \\
\hline 3rd High-voltage transmission line & 0.35 & ongoing \\
\hline 4rd High-voltage transmission line & 0.45 & planned \\
\hline Urban renewal of Colon & 0.57 & ongoing \\
\hline 3rd bridge over the canal & 0.57 & ongoing \\
\hline Metro line 3 & 2.60 & planned \\
\hline 4th bridge over the canal & 1.20 & planned \\
\hline Technical Institute (ITSE) & 0.20 & ongoing \\
\hline Private & 7.74 & \\
\hline Minera Panama & 5.50 & ongoing \\
\hline AES gas project & 1.15 & ongoing \\
\hline Gas to Power Panama (Martano) & 0.90 & ongoing \\
\hline Convention center Amador & 0.19 & ongoing \\
\hline Total & 16.68 & \\
\hline$\%$ of 2016 GDP & 30.26 & \\
\hline \multicolumn{3}{|l|}{ Sources: News and Fund staff calculations. } \\
\hline
\end{tabular}

The estimated direct and indirect growth contributions from investment projects in the existing pipeline are sizeable. We quantify the direct and indirect effect of each investment project on growth. The direct effect is estimated by the project's contribution to domestic activity. ${ }^{6}$ In addition, we estimate the indirect (quantifiable) effect using approximations for public investment multipliers found in the empirical literature. The overall output multipliers are estimated based on the short- and long-term output elasticities to public capital in Bom and Ligthard (2014). ${ }^{7}$ Moreover, our analysis builds on Born and Ligthard (2014) by allowing for project-specific output multipliers to reflect the fact that all types of investment do not produce the same indirect effects across the economy. Specifically, we adjust the overall multipliers in Born and Ligthard (2014) based on the relative magnitude of multipliers for different types of

\footnotetext{
${ }^{6}$ The import content of each project is estimated separately and goes from 30 percent in the case of the Colon renovation and the construction of the new technical institute (ITSE) to 70 percent in the case of the new Metro lines and the new gas power generation plants. Using this approach, the direct growth effect from the construction of ITSE, for instance, is estimated at US\$137 million, or about 0.24 percent of GDP.

${ }^{7}$ Bom and Ligthart (2014) present a survey of estimates found in 68 studies that aim to quantify output effects from public capital investment over the period 1983-2008. Our analysis uses the typical multiplier values presented by Bom and Ligthard (2014).
} 
investment projects estimated by Pereira and Pereira (2015). ${ }^{8}$ The direct contribution to economic growth from investment projects identified in Table 1 is estimated at about $2 \frac{1}{2}$ percentage points over 2017 and 2018 in the baseline scenario. In addition, the indirect contribution on economic growth through multiplier effects of these projects is estimated at $1 / 2$ percentage points on average over the period 2018-21.

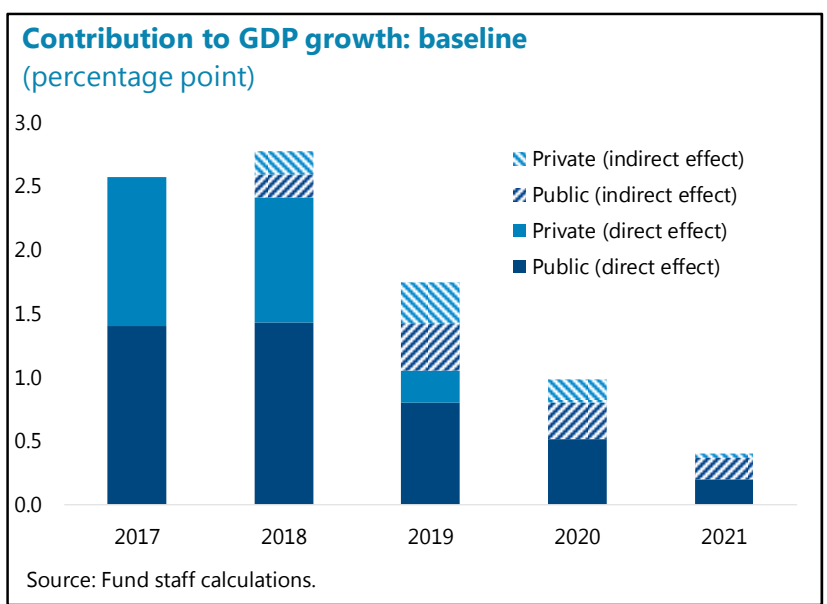

The estimated contribution of investment projects to economic growth is sensitive to the assumed timing of their completion and import content. To assess the sensitivity of the estimated growth effects to these assumptions, we consider an adverse scenario. The adverse scenario assumes three key differences with respect to the baseline: first, the import content of all investment projects is higher by 10 percentage points; second, the start of construction and the timeline for new projects is assumed to be shifted forward by one year; and third, the execution of ongoing projects is assumed to drop by $1 / 3$ in 2017 due to exogenous circumstances and project completion is correspondingly assumed to be delayed by one year. Such an adverse scenario is estimated to result in

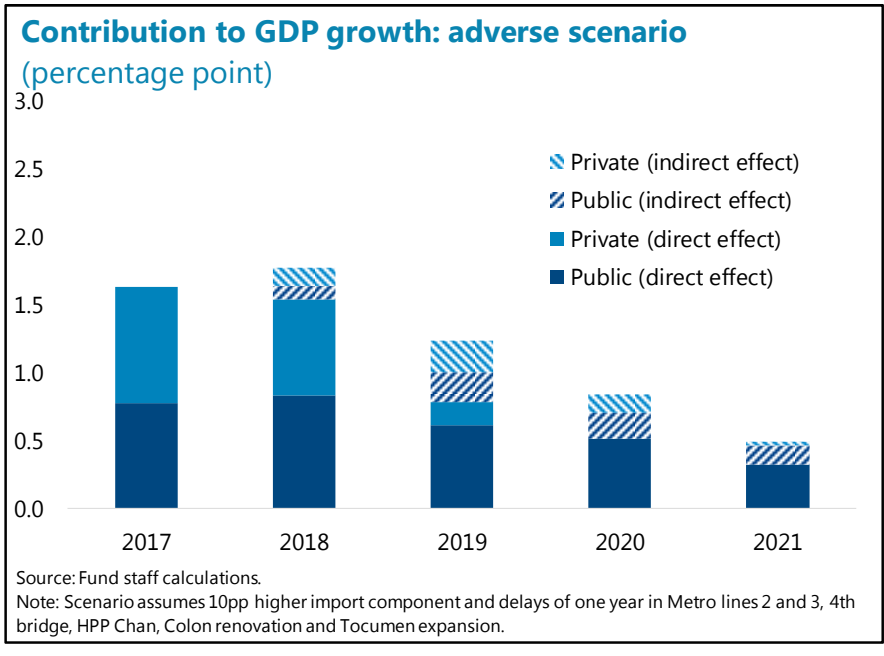
a lower growth contribution by about 1 percentage point per year.

Infrastructure investments are likely to result in productivity enhancements and strengthen potential growth prospects. In addition to the direct and indirect quantifiable effects, investment can improve the underlying functioning of the economy. For instance, the new metro lines can substantially shorten commuting time, lower street congestion, and generate additional commercial and construction activity by raising the attractiveness of remote areas because of improved connectivity. Energy investments in power generation can improve energy supply and potentially lower energy costs in production. Similarly, investments in new transmission lines can increase trading opportunities with neighbors, and thereby, improve efficiency of the electricity market and create extra revenues. In addition, the completion of the airport expansion

\footnotetext{
${ }^{8}$ Pereira and Pereira (2015) investigate the output elasticities of 12 different types of public infrastructure investments, such as railroads, ports, airports, health, education, and telecommunications for the case of Portugal. In our analysis, the largest multipliers are found for hospitals ( 0.16 in the following year), followed by telecommunications and energy infrastructure $(0.13)$, and road transportation $(0.07)$.
} 
can further strengthen Panama's attractiveness as an investment and tourism destination, and can offer synergies with other transportation modes to enhance the logistics sector (see Sections IV and V). While a precise quantification of these gains is not straightforward, they are likely to be significant, as suggested by anecdotal evidence about recent projects. For example, Metro Line I shortened commuting time for many workers and helped generate commercial activity in some areas.

Higher fiscal revenues are essential to support the financing of strategic public investment projects. With the public-sector accounting for over a half of the estimated value of the largescale investment projects in Table 1, a strong fiscal revenue base is needed to preserve space for planned investment. Nonetheless, despite a significant improvement registered in 2016, Panama's tax revenues remain among the lowest in the region and significantly below countries at similar levels of economic development. In this environment, recurrent spending may crowd out capital spending without further increases in tax revenues, thereby reducing growth contribution from investment.

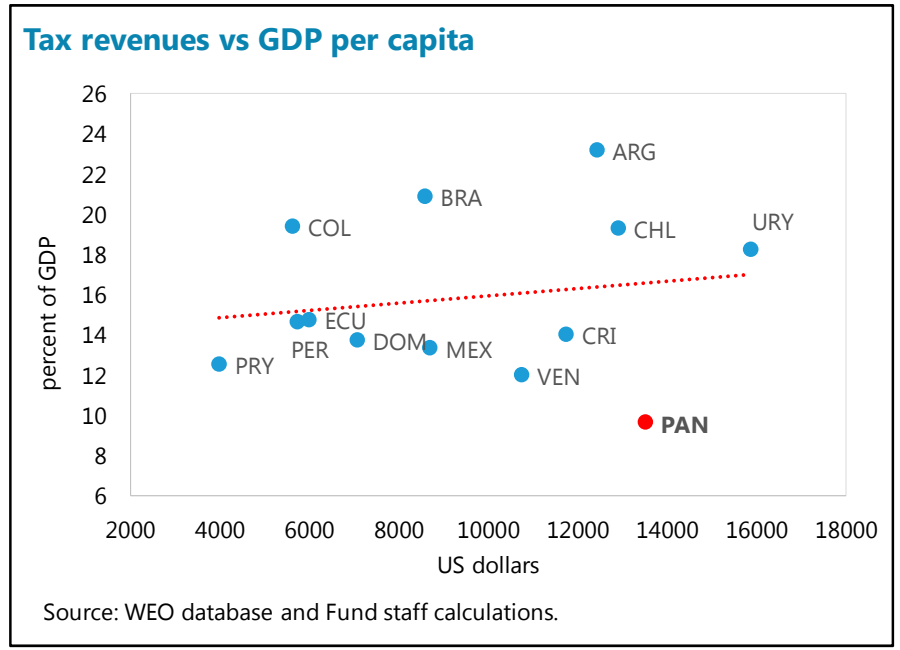

\section{B. Growth Accounting and Factors of Production}

Strong investment activity in recent years further boosted capital's dominance as a contributor to growth among production factors. A simple growth accounting exercise suggests that capital accounted for over half of total growth over the period 2008-15. ${ }^{9}$ This development reflects very strong private and public investment activity, which raised gross capital formation as a share of GDP from a trough of about 31 percent during the global financial crisis in 2009 to over 47 percent in 2014-15.

\footnotetext{
${ }^{9}$ The growth accounting exercise assumed an initial capital stock that is three times larger than Panama's GDP, labor elasticity of 0.6 and capital elasticity of 0.4 , and a depreciation rate of 5 percent per year.
} 
Based on the existing pipeline of investment projects, capital is projected to remain a key contributor to growth, albeit at a more sustainable pace. Gross capital formation, estimated at about 47 percent of GDP in 2016, is projected to gradually decline to a more sustainable level of about 42 percent of GDP over the medium term. In turn, capital's average contribution to growth will be about 1 percentage point lower than over the period 2008-15 and result in a slightly more moderate growth path. ${ }^{10}$ In this context, the projected slight

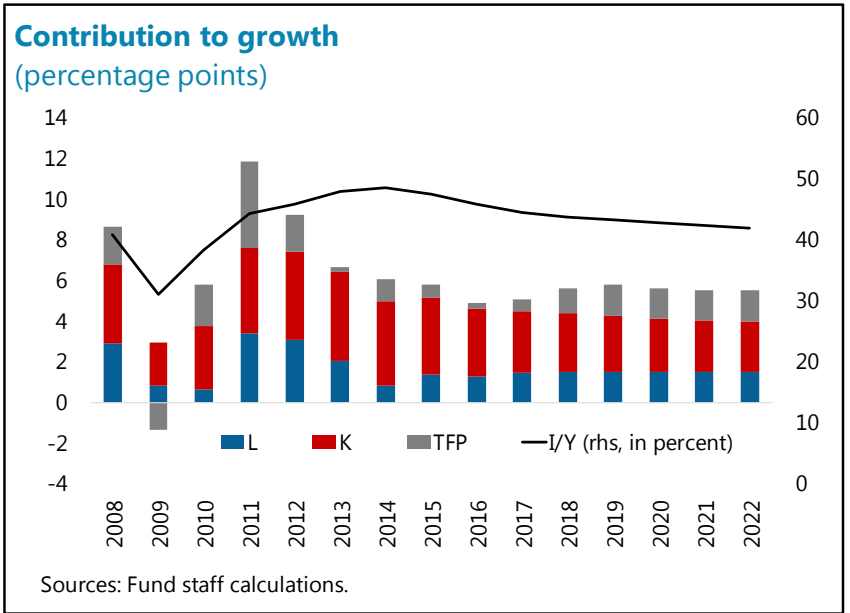
moderation of investment to more sustainable levels is the key factor explaining the revision of projected medium-term growth from about 6 percent in the 2016 Article IV consultation to about 5.5 percent in the 2017 consultation.

\begin{tabular}{l} 
Table 2. Growth Accounting: Estimated Average Contribution to Growth \\
$\qquad$\begin{tabular}{lllll}
\hline \\
\hline \multicolumn{5}{l}{ Contribution to growth by factors of production (percentage points) } \\
\cline { 2 - 6 } \\
\cline { 2 - 5 } $2008-2015$ & 1.88 & 3.75 & 1.31 & 6.93 \\
$2016-2022$ & 1.46 & 2.80 & 1.16 & 5.42 \\
\hline \hline
\end{tabular} \\
\hline
\end{tabular}

\footnotetext{
${ }^{10}$ Contributions from labor and total factor productivity (TFP) are also expected to be somewhat smaller than in recent years. Labor's contribution is expected to moderate somewhat from 1.9 percentage points over 2008-2015 to about 1.5 percentage points over 2016-2022, which is consistent with the projected slight decline in population growth. TFP is projected to contribute about 1.2 percentage points, very similar to its contribution of 1.3 percentage points over the period 2008-2015.
} 


\section{Transforming Panama into a Global Logistics Hub: What can Panama Learn FROM SINGAPORE?}

With the expanded Panama Canal, the associated transport and logistics infrastructure, the presence of the regional financial center, and a stable economic and political environment, Panama seems well placed to leverage its logistics sector as a source of future growth. This section considers Singapore's emergence as a global logistics center as a case study to identify lessons that Panama can draw upon to facilitate a similar transition.

Panama's unique geographical location has endowed it with a comparative advantage in logistics and transportation services. The interoceanic Canal, in particular, is an exceptional asset for leveraging development of logistics and transportation services given that about 5 percent of world merchandise trade transits the Canal. In addition, Panama has an extensive existing internal rail and road network connecting the two sides of the Canal that facilitate logistics and distribution. Panama's Tocumen International Airport also operates as a regional hub and offers opportunities for synergies with other modes of transportation.

Lessons from success stories on the world stage, such as Singapore's, can help Panama leverage its comparative advantage to transform Panama from a regional into a global logistics hub. Panama shares some important characteristics with Singapore: a favorable geographical location, economic and political stability, and openness to world trade. In addition, both countries have established port and airport connectivity as shown in Table 3. Such commonalities suggest that Panama can draw lessons from Singapore's transition into a global logistics hub to boost its logistics competitiveness and facilitate a similar transition.

\begin{tabular}{|c|c|}
\hline Singapore & Panama \\
\hline $\begin{array}{l}\text { Largest container transshipment port in the world, with } \\
\text { connections to over } 600 \text { ports }\end{array}$ & $\begin{array}{l}\text { First and second busiest ports in the region and second } \\
\text { largest free trade zone in the world (after Hong Kong) }\end{array}$ \\
\hline $\begin{array}{l}\text { Changi International Airport is a key node in the global } \\
\text { air-transport network: }\end{array}$ & $\begin{array}{l}\text { Tocumen International Airport acts an important } \\
\text { regional hub: }\end{array}$ \\
\hline $\begin{array}{l}\text { Voted by air travelers as the best airport in the } \\
\text { world for the fourth consecutive year in } 2016 \\
\text { (Skytrax World Airport Rewards) }\end{array}$ & $\begin{array}{l}\text { Busiest airport in Central America and one of } \\
\text { the airports with the highest number of } \\
\text { passengers in Latin America and the Caribbean }\end{array}$ \\
\hline $\begin{array}{l}\text { About } 7,000 \text { weekly flights to } 330 \text { cities in } 90 \\
\text { countries and territories worldwide }\end{array}$ & Flights to over 80 cities in 35 countries \\
\hline Trade activity represents over 300 percent of GDP & $\begin{array}{l}\text { Trade is concentrated in services and represents about } \\
60 \text { percent of GDP }\end{array}$ \\
\hline
\end{tabular}




\section{A. Singapore's Success Story}

Singapore's transformation into a global logistics hub has promoted sustained and broad-based economic growth. Since gaining independence in 1965, Singapore's transformation into a central node on the world trade map has resulted in a broad economic expansion (text figure) that included different economic sectors. Singapore's model of development capitalized on important synergies between related sectors including transportation and storage, financial intermediation, insurance, and information and communication

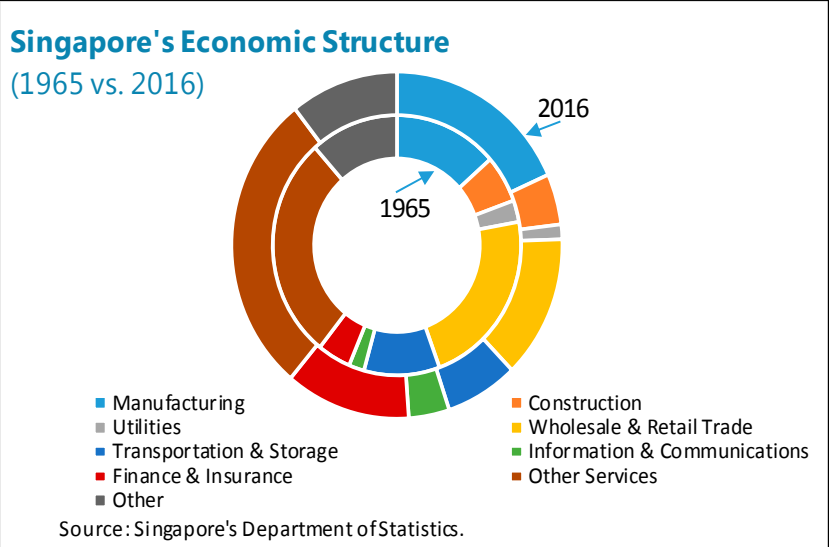
technologies. Consistent with the growth strategy focused on these related sectors, they were the key drivers of economic activity. The development of the world-class services sector also produced positive spillovers into manufacturing and construction and contributed to a broadbased expansion of economic activity.

The continued re-invention of Singapore's model helped sustain double-digit growth in various sectors. The ability to add new activities and facilitate incremental changes contributed to maintaining strong growth in both services and industry. In addition, various segments of the services sector registered double-digit growth rates, set against the backdrop of positive synergies and mutual reinforcement among transport and logistics, financial intermediation, insurance, and ICT (Figure 6).

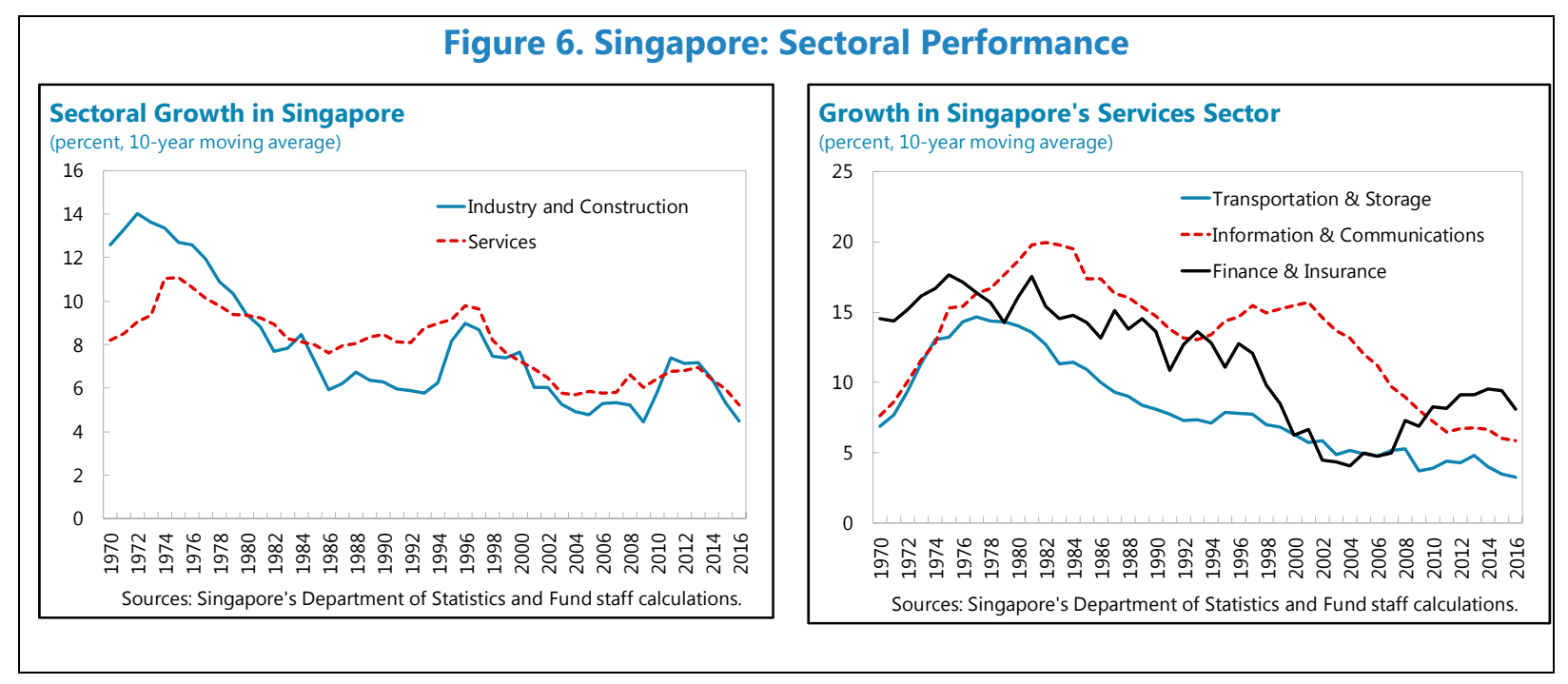


Singapore's success story reflects its ability to leverage its strategic geographical location through synergies between public policy and private sector involvement. Lam and Ramakrishnan (2017) elaborate that Singapore's successful transformation into a global logistics hub has been the result of three key factors: connectivity, world-class infrastructure, and encouragement of private sector participation. First, connectivity has been strengthened as the maritime and civil aviation authorities expanded Singapore's maritime and flight connections network through enhanced cooperation with foreign authorities, shipping companies, and the conclusion of aviation agreements with over 130 states and territories. At the same time, the country built an extensive network of free-trade agreements with over 30 economies, which further boosted its connectivity. Second, infrastructure has been continually strengthened with one of the largest and most sophisticated ports in the world, an airport that facilitates air cargo with the latest technological solutions for storage of perishable and sensitive materials, and the world's first single window system to support trade facilitation and streamline issuance of permits. Third, the authorities have encouraged direct involvement of the private sector in public decision-making process. For instance, public investment projects have been subject to an extensive consultation process to ensure that they meet the business sector's needs and can induce private investment in complementary infrastructure.

\section{B. Where Does Panama Stand?}

With adequate policy actions Panama has an opportunity to follow Singapore's example. Panama's connectivity is at the top in the region, with the two busiest ports in the region, Tocumen International Airport as the regional air-transport hub, and many important telecommunication/internet optical fiber cables passing through the Canal. Numerous multinational companies have chosen Panama for HQs of their (regional) operations, and its dynamic financial center can provide necessary impetus to strengthen synergies across sectors. Panama has also concluded over a dozen free-trade agreements that cover trade relations with over 40 countries and territories (including with Singapore).

The expanded Canal is expected to unlock new growth opportunities. The expanded Canal opens opportunities for emerging activities, such as LPG and LNG vessels, which are among the fastest-growing user segments. and may have spillovers to related industries. In particular, the Canal could support further development of Panama's ports and logistics industry, provided it does not cannibalize such activity as the larger vessels transit directly from source to destination, especially between Asia and North America. Continued improvements in infrastructure and capacities to offer new services are likely to be the key components of a strategy to maintain and enhance Panama's position as an attractive destination for logistics and distribution.

Panama has narrowed its gap in container traffic and shipping connectivity relative to the world's major ports (Figure 7). While total container traffic through Panama's ports is about one fifth of Singapore's, Panama's growth has been significantly faster than Singapore's over the last decade. Panama has also managed to narrow its connectivity gap relative to the world's top 
ports over the last decade according to the World Bank's liner shipping connectivity index, though it still lags behind all 5 top ports.

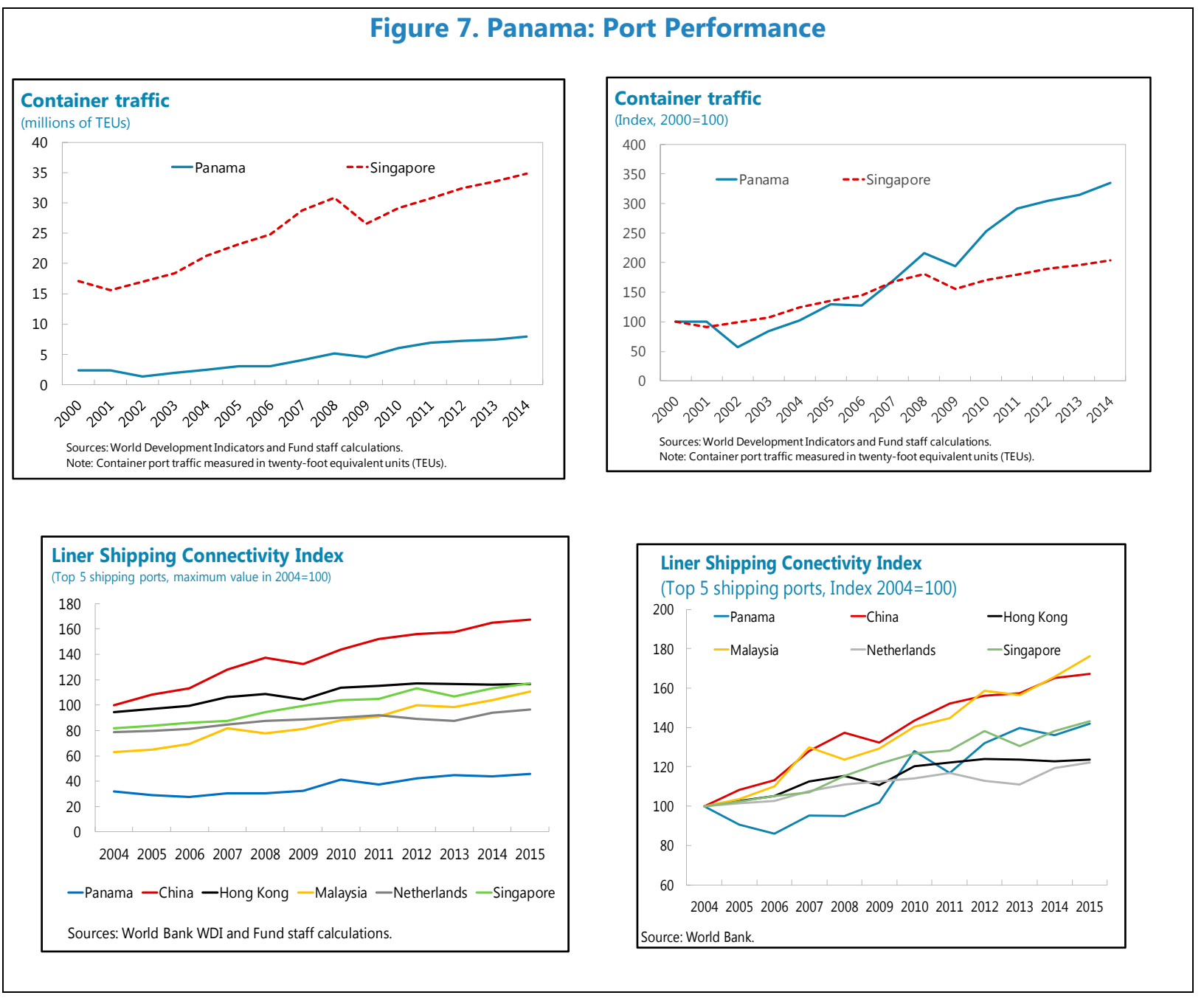

Panama's significant improvement in logistics performance over the last decade has established its competitive advantage as a logistics hub compared to its neighbors in Latin America, though still significantly behind Singapore. The Logistics Performance Index suggests that Panama's progress since 2007 was broad-based, with improvement in logistics quality and competence, cross-border shipments, infrastructure and customs. Panama has also managed to narrow its gap relative to Singapore in many areas relevant for logistics performance, such as cross-border shipping, infrastructure, and logistics quality and competence (Figure 8). Nonetheless, a significant gap remains in most logistics segments, including customs efficiency, timeliness, tracking and tracing, and infrastructure. ${ }^{11}$

\footnotetext{
${ }^{11}$ Closing the LPI gap relative to Singapore implies reducing the distance to the global frontier as Singapore is consistently among the world's top performers on various logistics indicators.
} 


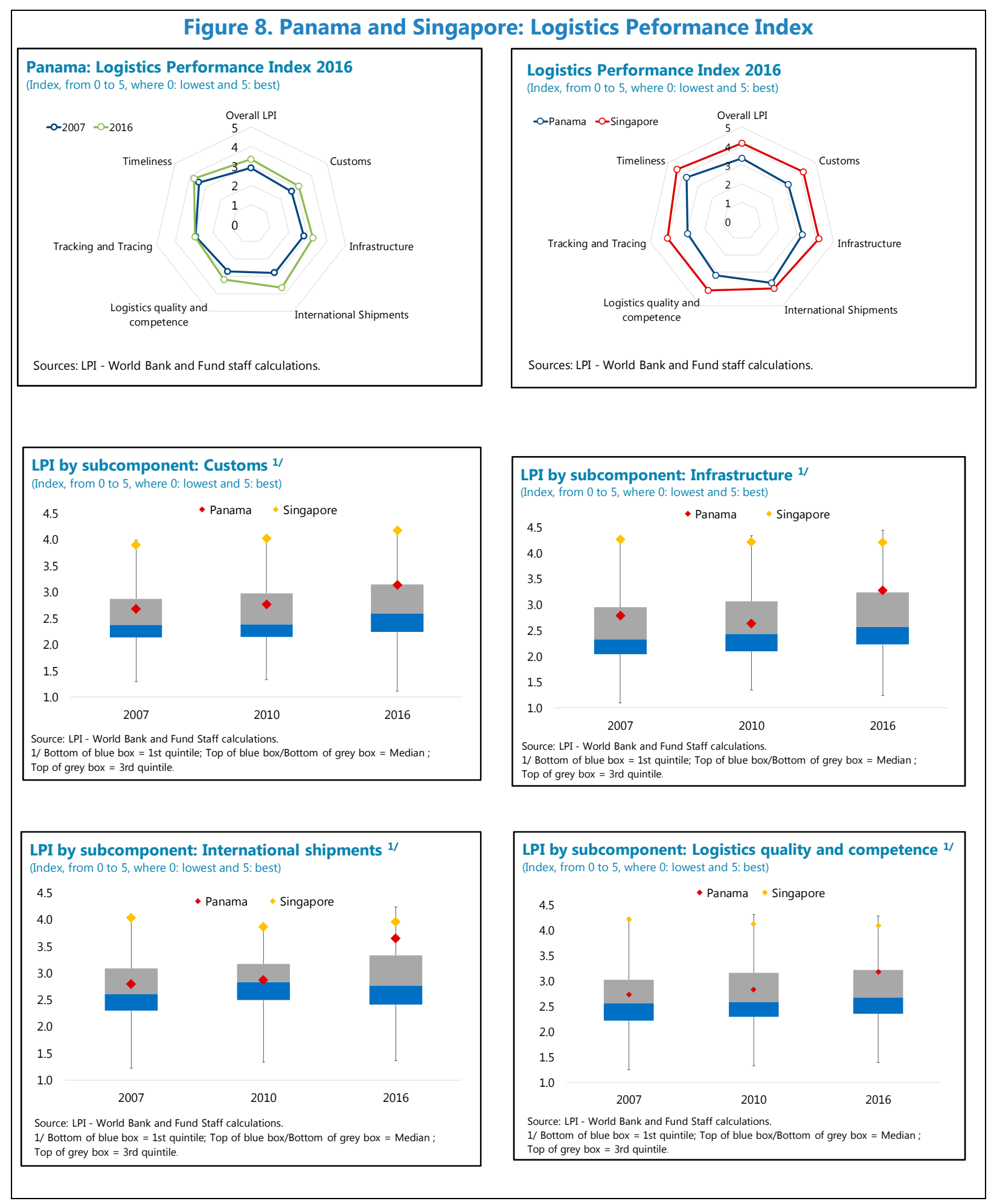

More generally, policy actions that strengthen the business environment and improve competitiveness also incorporate key measures that are needed to address challenges in transforming Panama into a global logistics hub. Such policy areas include general strengthening of institutions, enhancements in the education system and infrastructure quality, 
strengthened contract enforcement, better capacities to absorb new technologies, and the promotion of a culture of paying taxes (Figure 9). Beyond the narrow area of improving logistics performance, effective measures to tackle challenges in these policy areas are likely to also boost Panama's opportunities in other economic sectors, create synergies, and help Panama continually re-invent its business model.

Figure 9. Panama and Singapore: Survey-based Competitiveness Indictors
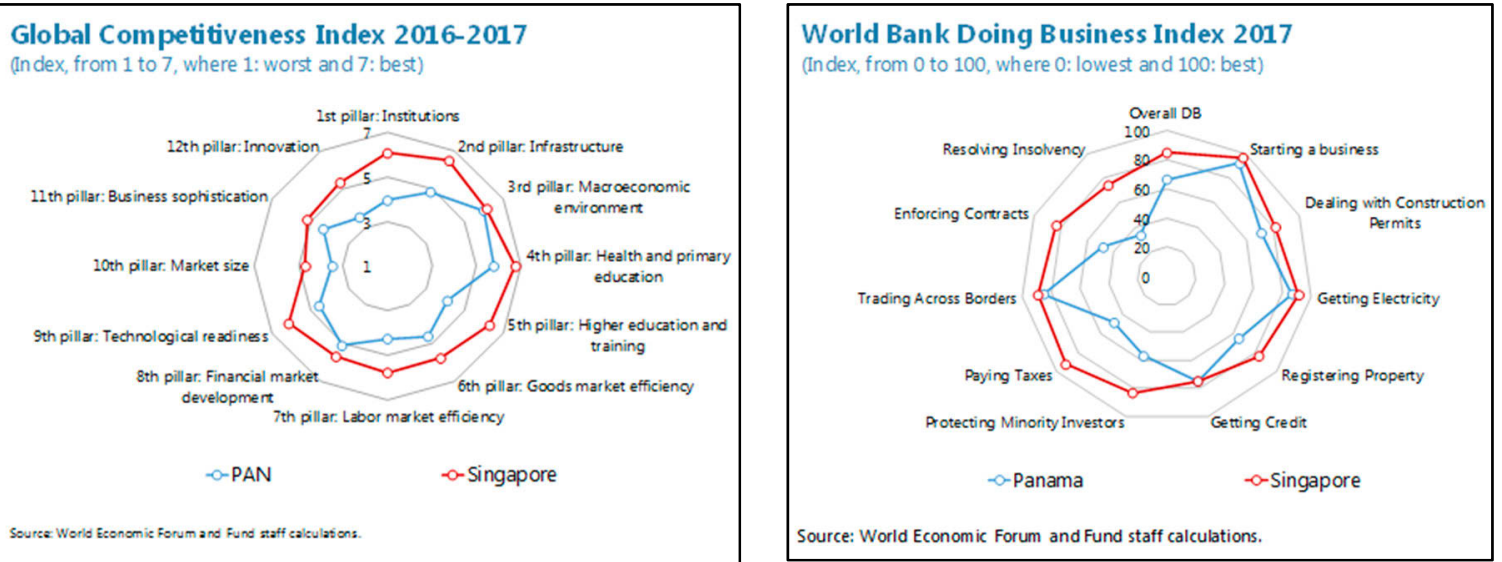


\section{LeVERAgING CONNECTIVITY TO STRENGTHEN TOURISM}

Tourism is an important, yet underdeveloped, sector in the Panamanian economy. Panama has an advantageous climate and diverse ecosystem combined with a major metropolitan area attractive to a diverse tourism clientele. With Panama's role as a regional transportation hub, there is a unique opportunity to leverage Panama's connectivity to strengthen its tourism industry. This section takes stock of the Panamanian tourism sector, its competitiveness and recent performance and makes concrete recommendations to leverage Panama's existing strategic advantages to boost the economic contribution of the sector and diversify its product in support of Panama's inclusive growth objectives.

\section{A. Panama's Tourism Sector - Taking Stock}

Tourism is an important sector in the Panamanian economy, yet underrecognized as such. The World Travel and Tourism Council (WTTC) estimates that tourism's total contribution to output is a sizeable 17 percent of GDP. ${ }^{12}$ While Panama is not widely appreciated as a tourist destination, this is larger than the average of the tourism-dependent economies of the Caribbean as well as Panama's neighbors in Central America. The tourism industry is also a major employer: tourism is estimated to account for about 12 percent of total employment, making it one of the largest employment-generating industries in Panama (Figure 10). About 3 percentage points of the contribution of tourism to employment is directly related to jobs in hotels and restaurants and other tourist activities, while the remainder is associated with supply-chain effects from tourism's linkages with other industries.

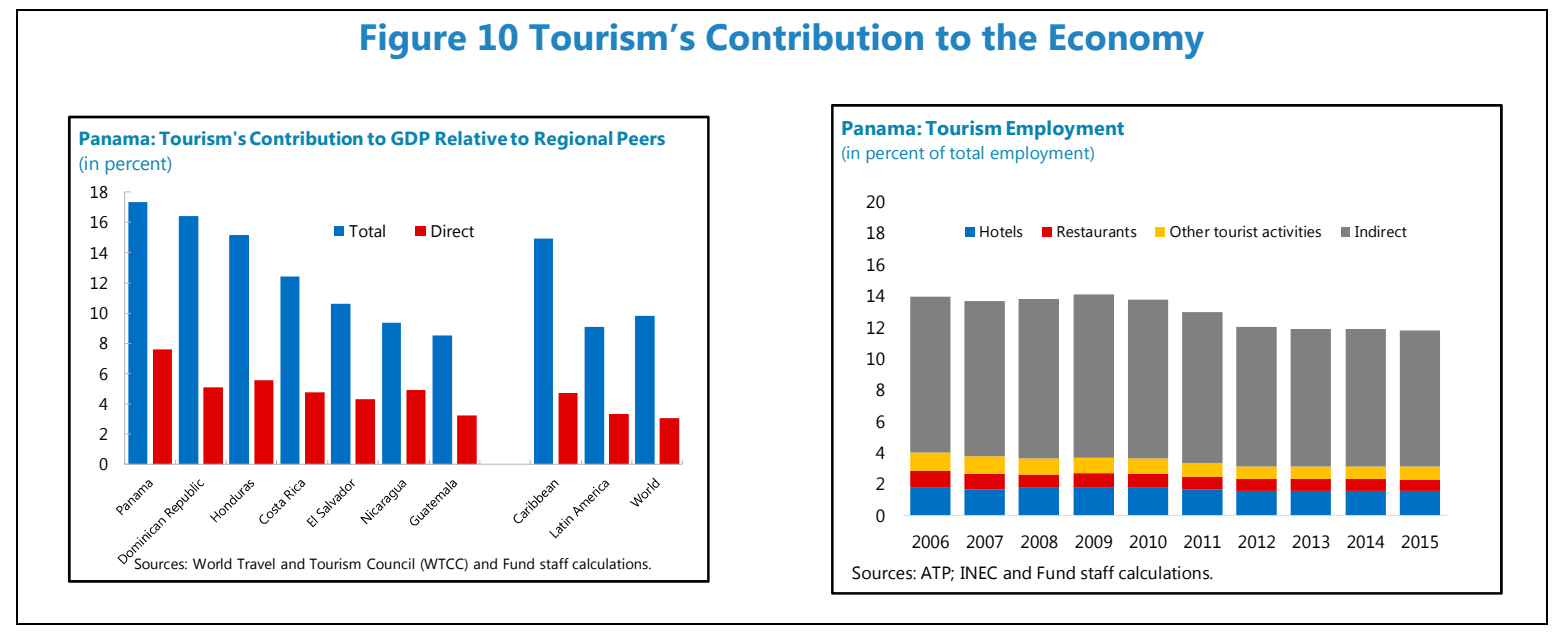

\footnotetext{
${ }^{12}$ The total effect includes activity directly related to the tourism industry, estimated at about 8 percent of GDP, as well as spillover effects from the tourism onto other industries, estimated at about 9 percent of GDP. These latter effects included the sum of capital investment spending by all industries directly involved in travel and tourism, government spending in support of tourism (including promotion and visitor information services) and supply-chain effects from purchases of domestic goods and services directly by different industries within travel and tourism as inputs to their final tourism output.
} 
Tourism performance is closely tied to economic developments in Latin America and the Caribbean where the majority of tourists to Panama originate from. Almost 60 percent of tourists originate from the region. South America is by far the most important market: 46 percent of total arrivals in 2015 originated in South America compared to 10 percent from Central America and 2 percent from the Caribbean. ${ }^{13}$ South America's market share expanded rapidly from 2006 to 2013 as the region's commodity exporters benefited from the commodity price boom and expanded their demand for Panama's tourism services. The increase in market share partially reversed course beginning in 2014 as the region began to adjust to the sharp drop in commodity prices that began that year, but, in 2015, South American tourists still accounted for 11 percentage points more of total tourist arrivals than they had in 2006. The more recent loss of market share is also likely related to the sharp depreciation of the region's currencies relative to the U.S. dollar, which has

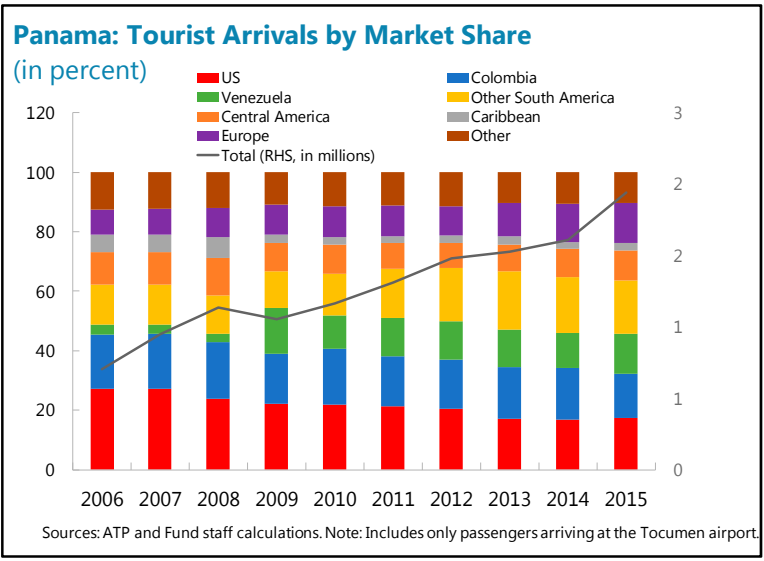
made Panama a more expensive destination for the region's tourists. ${ }^{14,15}$ The region is expected to gradually emerge from its regional recession in 2017 , but with commodity prices expected to remain low, the regional outlook remains relatively subdued, suggesting that any impact on demand for Panama's tourism services is likely to be limited. ${ }^{16}$

The U.S. is also an important market for Panamanian tourism (Figure 11). In 2015, 17 percent of tourism to Panama originated in the U.S. However, the importance of the U.S. market has declined over time: its market share declined about 10 percentage points since 2006 . This decline is the direct counterpart of the rise in importance of the Latin American and Caribbean market and reflects the strong growth of that segment compared to the U.S. market rather than a decline in tourists from the U.S. More generally, dollarization has been a boon to the U.S. segment, generating stability in the price of the Panama's tourism product for U.S. tourists. In this context, trends in U.S. arrivals appear to have been primarily driven by developments in the

\footnotetext{
${ }^{13}$ Data on the country of origin of tourists to Panama is only available for those tourists arriving through the Tocumen airport and excludes cruise passengers and passengers arriving by land. With passengers arriving by land representing 6 percent of total arrivals, the market share of Latin America and the Caribbean tourist in Panamanian tourism is likely understated by these statistics.

${ }^{14}$ Colombia, which represents about 30 percent of South American arrivals or 15 percent of total arrivals, accounted for the majority of the decline in the region's overall market share.

${ }^{15}$ Laframboise and others (2014) show that tourism arrivals and expenditure are sensitive to both price and income factors in source markets.

${ }^{16}$ The January World Economic Outlook from the IMF projected growth of 1.2 and 2.1 percent for the Latin American and Caribbean region for 2017 and 2018, respectively.
} 
U.S. economic cycle and, with the U.S. recovery poised to continue, should drive a continued increase in arrivals from the U.S. market. ${ }^{17}$

Figure 11. Tourism Arrivals by Market
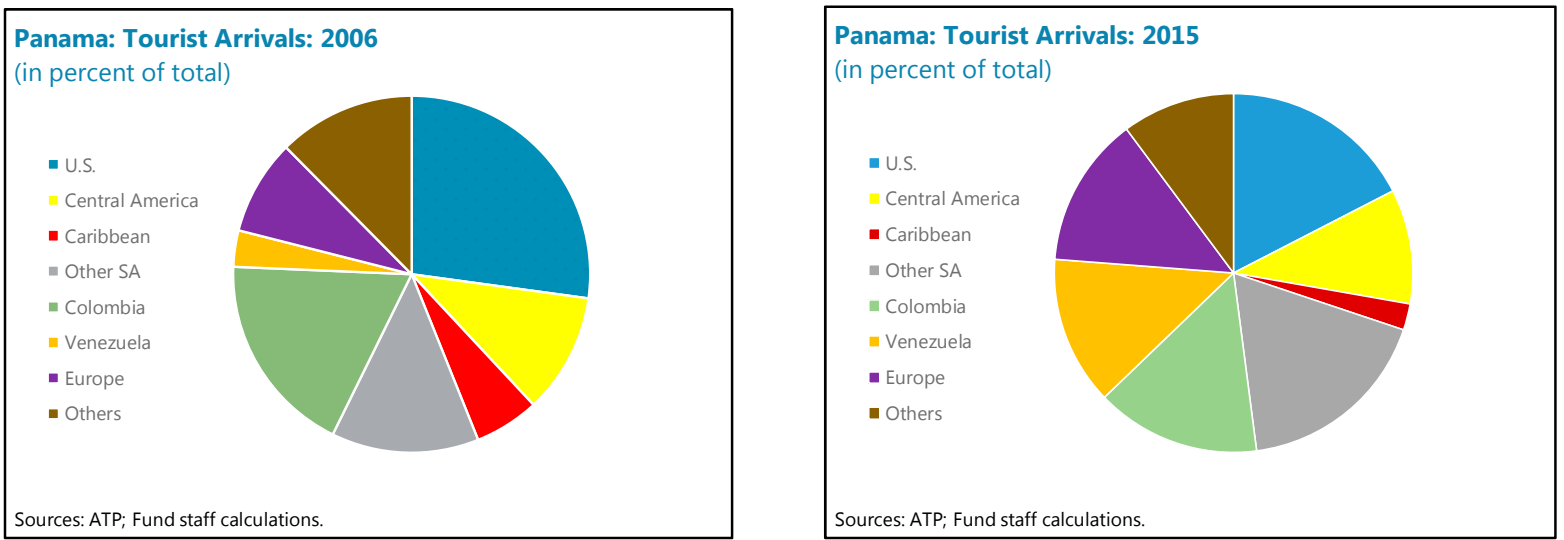

Leisure travel dominates visitors' motivation for travelling to Panama. Business travel, including for conventions, has also traditionally been an important factor driving tourists to Panama and, with a new convention center nearing completion, this segment is expected to increase in importance going forward. ${ }^{18}$ Tourism remains concentrated in Panama City, which with the development of the retail industry, has transformed Panama City into a major shopping destination for Latin America. While data on the

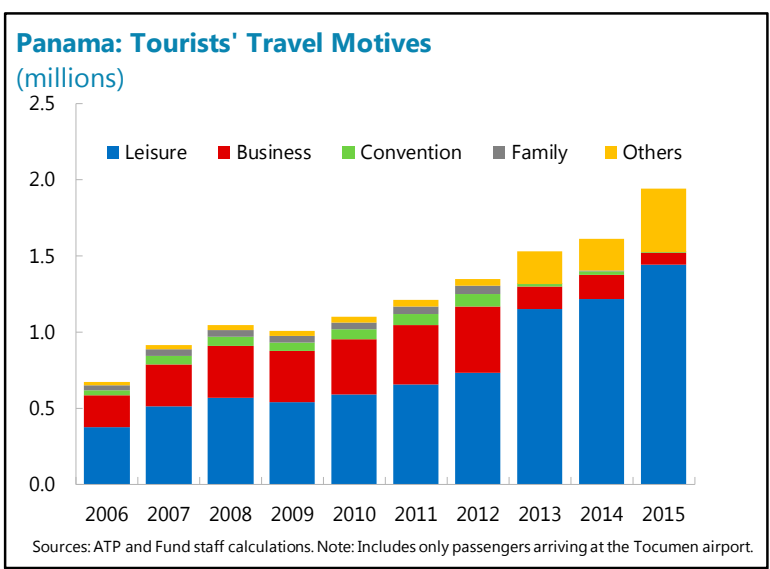
percent of room stock is not available, over 40 percent of tourist accommodations are located in Panama City. Given the concentration of large hotels in the capital, this likely significantly understates the importance of Panama City as the main tourist destination within Panama. Tourism remains under-developed throughout the remainder of Panama, although Chiriqui and Bocas del Toro have grown in popularity. On average, tourists tend to stay in Panama for about 8 and a half days and spend about US\$270 a day or over US\$2300 for the duration of their stay.

Panama remains an affordable travel destination. The appreciation of Panama's real effective exchange rate, driven to a large extent by the appreciation of the U.S. dollar, has diminished the price competitiveness of Panama's tourism industry; however, other indicators

\footnotetext{
17 The January World Economic Outlook from the IMF projected growth of 2.3 and 2.5 percent for the United States for 2017 and 2018, respectively.

${ }^{18}$ While the importance of business travel appears to have declined since 2013, this appears to be related to a statistical issue rather than a general trend.
} 
suggest that Panama remains an affordable destination (Figure 12). The 'Week-@-the-Beach' (W@tB) Index compares nominal-in-country costs of a typical basket of beach/holiday goods/services with common standards, from a common source and in a common currency (Laframboise and others 2014 updated to January 2017). The index suggests that Panama compares favorably in price to Central and South American destinations and the tourismdependent Caribbean. However, Panama's relative performance in the index may be distorted by differences across tourism products: while the tourism offerings of regional comparators are primarily concentrated in relatively more high-end beach resorts, Panama's tourism industry has primarily been driven by tourism to Panama City as a shopping destination. In this context, Panama's REER may better reflect developments in the relative competitiveness of its tourism industry. 


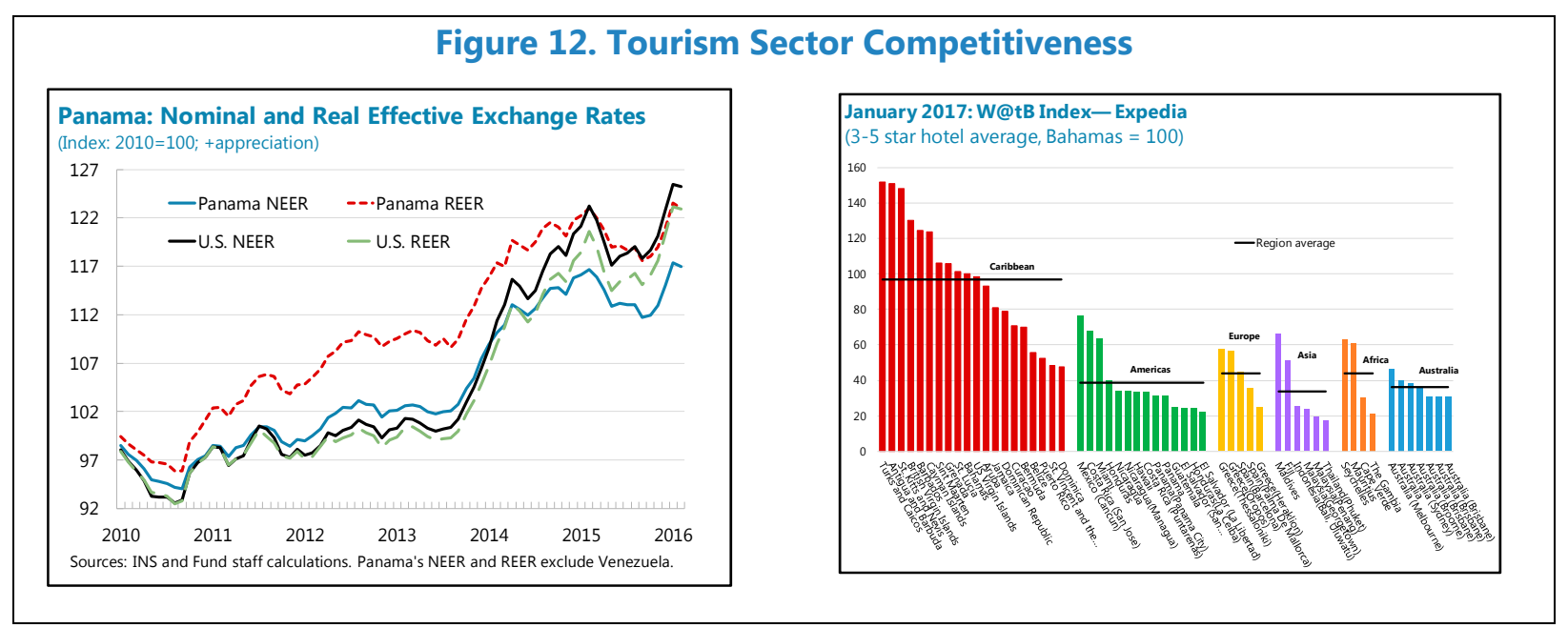

\section{B. Performance of the Tourism Sector}

Tourism performance has been affected by regional developments and the appreciation of the U.S. dollar. Total tourism arrivals declined in 2016 relative to their earlier year level as the industry was hurt by the recession in Latin America and the appreciation of the U.S. dollar. Hotel occupancy rates (at 52 percent in 2015) are also low, although this primarily reflects historical over-investment in the hotel room stock, particularly in Panama City, rather than the downturn in arrivals. However, despite the decline in arrivals, tourism receipts rose by 5.6 percent, down from 12.8 percent in 2015. As a result, Panama continued to grow its market share of total tourism expenditure in Latin America and the Caribbean, both in leisure and business tourism. Relative to tourism competitors in CAPDR, however, Panama's market share has been stable since 2012 .

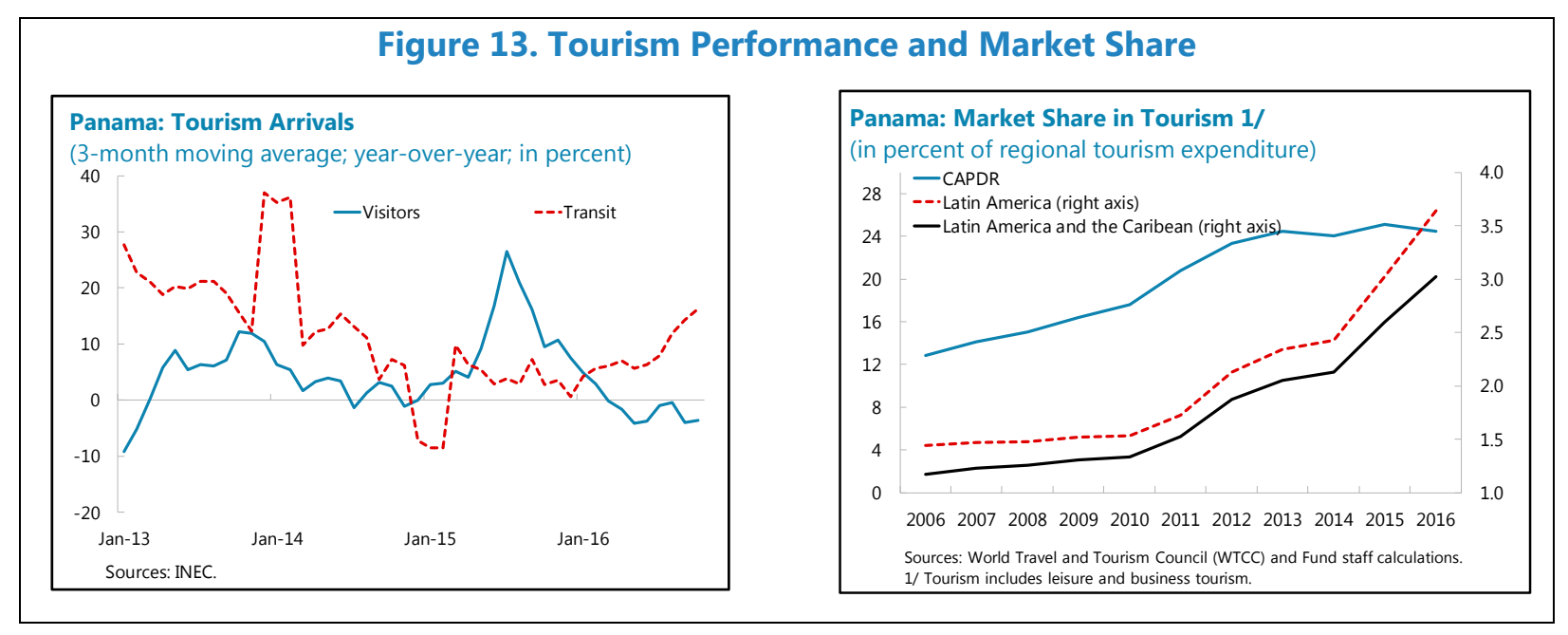




\section{Opportunities to Strengthen Panama's Tourism Sector}

Panama is well positioned to grow its tourism sector. Relative to other tourist destinations in the region, Panama has two important comparative advantages that have yet to be fully exploited: (1) its strategic geographical position that has transitioned Panama into a regional transportation hub and (2) an advantageous climate and diverse ecosystem combined with a major metropolitan area attractive to a diverse tourism clientele.

Panama's connectivity should be leveraged to enhance the tourism sector. Panama's Tocumen airport is a regional hub, but only about 10 percent of travelers transiting through the airport visit Panama. With tourists spending an average of US $\$ 270$ a day, capturing even a small share of transiting passengers as tourists holds considerable potential to boost economic growth. The ongoing extensive expansion of the Tocumen airport, expected to be opened in 2018, provides an opportunity to capitalize on the increased volume of transiting passengers through the Tocumen airport to grow the domestic tourism sector. The expansion will boost airlift supply, which Acevado and others (2015) have shown to be the most effective way to boost tourist arrivals on sustained basis. Iceland offers potential important lessons for Panama in this regard. Through strategic partnerships with airlines, including through free stopovers, Iceland has successfully increased tourism by marketing itself as a stopover destination for passengers transiting to other destinations. In addition, the opening of the expanded Canal provides an opportunity to grow the cruise segment. To successfully develop the cruise segment, supporting infrastructure will need to be put in place. Positioning Panama as a home port, through the development of a new cruise terminal, could pay dividends in this regard.

Diversifying Panama's tourism product can support tourism development and inclusive growth. Tourism to Panama remains concentrated in Panama City despite the attractiveness of Panama's diverse ecosystem for the development of a broad range of tourism products including beach and eco-tourism. Diversifying the tourism product with require enhancing connectivity within Panama to support development of the sector outside of Panama City. Otherwise, a two-pronged strategy is needed that focuses both on strengthening marketing efforts of Panama's diversified tourism product while encouraging development of tourism operators. Development of the cruise industry also has potential to have spillover effects to facilitate diversification of Panama's tourism product as new products may be developed in response to cruise passengers' demand for diverse excursions. Finally, diversifying Panama's tourism beyond Panama City, where it has been concentrated, can also support inclusive growth and a reduction in the significantly higher poverty rates in rural areas it may also encourage diversification of Panama's main tourism markets and help to reduce spillovers to Panama from developments in individual tourism source markets. 


\section{Conchusions}

Panama is well-placed to maintain its business model founded on its competitive advantage as an attractive destination for international financial, business and transportation services. Panama's historical success has been based on its strategic geographical position, which has been exploited to transform Panama into a transportation hub, while the favorable business environment has facilitated Panama's emergence as a regional business center. To further cement Panama's competitiveness, the results of the growth diagnostics exercise point to the need to improve the quality of education, strengthen governance and reduce bureaucracy. The most important challenge will be to advance reforms to the education system to ensure that it is able to supply workers with the skills demanded in Panama's economy, particularly as Panama continues its transition to a modern service-based economy.

Panama's connectivity can be leveraged to strengthen its logistics and tourism industries. Panama shares some characteristics with Singapore: a favorable geographical location, economic and political stability, a network of free trade agreements, and established port and airport connectivity. Thus, Panama could draw on lessons from Singapore's transition into a global logistics hub to boost its logistics competitiveness. The expanded Canal could also support further development of Panama's ports and logistics industry, provided it does not cannibalize such activity as the larger vessels transit directly from source to destination, especially between Asia and North America. The tourism industry has high potential for growth based on Panama's connectivity. Tocumen airport is an important regional hub, but only about 10 percent of travelers transiting through the airport visit Panama. Capturing even a small share of transiting passengers as tourists holds considerable potential to boost economic growth. In addition, the expanded Canal provides an opportunity to grow the cruise segment. Diversifying Panama's tourism beyond Panama City, where it has been concentrated, by developing beach and eco-tourism can also support inclusive growth and a reduction in the significantly higher poverty rates in rural areas. 


\section{REFERENCES}

Acevedo, Sebastian, Lu Han, Hye Sun Kim, and Nicole Laframboise. 2016. "Flying to Paradise: The Role of Airlift in the Caribbean Tourism Industry". IMF Working Paper No. 16/33.

Bom, P.R.D. and J.E. Ligthart (2014), "What Have We Learnt from Three Decades of Research on the Productivity of Public Capital?", Journal of Economic Surveys, 28 (5), pp. 889-916.

Cerra, Valerie, Alfredo Cuevas, Carlos Goes, Izabela Karpowicz, Troy Matheson, Issouf Samake, and Svetlana Vtyurina. 2016. "Highways to Heaven: Infrastructure Determinants and Trends in Latin America and the Caribbean,” IMF Working Paper No. 16/185.

Hausmann, R., L. Espinoza, and M.A. Santos (2016), "Shifting Gears: A Growth Diagnostic of Panama”, HKS Faculty Research Working Paper 16-045, Harvard University.

International Monetary Fund (2016), "Panama: Selected Issues”, International Monetary Fund Country Report 16/388.

Laframboise, Nicole, Nkunde Mwase, Joonkyu Park, Yingke Zhou. 2014. "Revisiting Tourism Flows to the Caribbean: What is Driving Arrivals?’. IMF Working Paper No. 14/229.

Lam, Y.Y. and K. Ramakrishnan (2017), "Three Factors That Have Made Singapore A Global Logistics Hub", Transport for Development Blog, World Bank.

Manpower (2016), “2016/2017 Talent Shortage Survey”, ManpowerGroup.

Pereira, A.M. and R.M. Pereira (2015), "Is All Infrastructure Investment Created Equal? The Case of Portugal", Working Paper 156, The College of William and Mary.

The Economist (2011), “Panama’s Economy: A Singapore for Central America?”, July 14, 2011. 